\title{
Characterizing the reproductive transcriptomic correlates of acute dehydration in males in the desert-adapted rodent, Peromyscus eremicus
}

\author{
Lauren Kordonowy ${ }^{*}$ (D) and Matthew MacManes
}

\begin{abstract}
Background: The understanding of genomic and physiological mechanisms related to how organisms living in extreme environments survive and reproduce is an outstanding question facing evolutionary and organismal biologists. One interesting example of adaptation is related to the survival of mammals in deserts, where extreme water limitation is common. Research on desert rodent adaptations has focused predominantly on adaptations related to surviving dehydration, while potential reproductive physiology adaptations for acute and chronic dehydration have been relatively neglected. This study aims to explore the reproductive consequences of acute dehydration by utilizing RNAseq data in the desert-specialized cactus mouse (Peromyscus eremicus).

Results: We exposed 22 male cactus mice to either acute dehydration or control (fully hydrated) treatment conditions, quasimapped testes-derived reads to a cactus mouse testes transcriptome, and then evaluated patterns of differential transcript and gene expression. Following statistical evaluation with multiple analytical pipelines, nine genes were consistently differentially expressed between the hydrated and dehydrated mice. We hypothesized that male cactus mice would exhibit minimal reproductive responses to dehydration; therefore, this low number of differentially expressed genes between treatments aligns with current perceptions of this species' extreme desert specialization. However, these differentially expressed genes include Insulin-like 3 (Ins|3), a regulator of male fertility and testes descent, as well as the solute carriers Slc45a3 and Slc38a5, which are membrane transport proteins that may facilitate osmoregulation.
\end{abstract}

Conclusions: These results suggest that in male cactus mice, acute dehydration may be linked to reproductive modulation via Insl3, but not through gene expression differences in the subset of other a priori tested reproductive hormones. Although water availability is a reproductive cue in desert-rodents exposed to chronic drought, potential reproductive modification via Insl3 in response to acute water-limitation is a result which is unexpected in an animal capable of surviving and successfully reproducing year-round without available external water sources. Indeed, this work highlights the critical need for integrative research that examines every facet of organismal adaptation, particularly in light of global climate change, which is predicted, amongst other things, to increase climate variability, thereby exposing desert animals more frequently to the acute drought conditions explored here.

Keywords: Adaptation, Testes, Genetics, Transcriptomics, Differential expression, Reproduction, Physiology, Dehydration, Cactus mouse, Peromyscus eremicus

\footnotetext{
*Correspondence: lauren.kordonowy@unh.edu

Department of Molecular, Cellular, and Biomedical Sciences, University of

New Hampshire, Rudman Hall (MCBS), 46 College Road, Durham 03824, NH

USA
}

(c) The Author(s). 2017 Open Access This article is distributed under the terms of the Creative Commons Attribution 4.0 International License (http://creativecommons.org/licenses/by/4.0/), which permits unrestricted use, distribution, and reproduction in any medium, provided you give appropriate credit to the original author(s) and the source, provide a link to the Creative Commons license, and indicate if changes were made. The Creative Commons Public Domain Dedication waiver (http://creativecommons.org/publicdomain/zero/1.0/) applies to the data made available in this article, unless otherwise stated. 


\section{Background}

For decades, evolutionary biologists have successfully described examples where natural selection has resulted in the exquisite match between organism and environment (e.g. Salinity adaptations in three-spine sticklebacks: [1, 2]; high-altitude adaptations for hemoglobin in deer mice and humans: [3, 4]; and Peromyscus adaptations for multiple environments: [5-7]). The match between organism and environment must be studied in the context of both components of fitness: survival and reproductive success, because both aspects of selection are critical to long term persistence in a given environment. Habitat specialists must possess phenotypes enabling survival and successful reproduction; therefore, cases where environmental selective pressures result in reduced reproductive success (e.g. [8-11]), but not survival, demand attention. Species occupying extreme environments are likely more vulnerable to the bifurcation of these two components of fitness. Moreover, long-term events like global climate change are predicted to increase climate variability and may enhance the challenges faced by species living on the fringes of habitable environments [10-14].

Deserts present extraordinary environmental impediments for habitation, including extreme heat, aridity, and solar radiation. Examples of well-described desert mammal behavioral adaptations are seasonal torpor (reviewed in $[15,16])$, nocturnality (e.g. $[17,18]$ ) and burrowing (reviewed in $[19,20]$ ) to avoid high temperatures and sun exposure. Desert mammals also exhibit a wide range of morphological adaptations, including large ears for effective heat dissipation (e.g. [21, 22]), metabolic water production (e.g. [23]; reviewed in [24]), and renal adaptations to minimize water-loss (e.g. [25-27]). Although desert rodents must possess adaptations conferring survival and reproductive benefits, researchers have focused on their physiological adaptations for survival. For example, renal adaptations in species of Kangaroo rats (Dipodomys species) have been described and explored for over 60 years [27-30]. While early research determined the renal physiology for Kangaroo rats $[27,29,31]$, recent research has focused on the genetic underpinnings of this phenotype [28, 30, 32], which is indicative of a larger methodological shift in the approach for examining adaptation.

Research in another desert-adapted rodent, Peromyscus eremicus (cactus mouse), has followed a somewhat different trajectory; however, it too has only pursued survival oriented physiological mechanisms (but see [33-35]). The ecology, physiology and behaviors of the cactus mouse in comparison with other Peromyscus species were summarized in 1968 [36], and the relationships between basal metabolic rate, body mass, and evaporative water loss were reviewed several decades later [37].
Known desert adaptations for cactus mouse include nocturnality and torpor (reviewed in $[38,39])$; however, the cactus mouse does not possess the same elaborate kidney structures responsible for renal adaptations in kangaroo rats [40, 35]. The physiological renal adaptations in $P$. eremicus have not been described in detail, despite considerable explorations of other aspects of this species' biology (reviewed in $[38,39]$ ). In order to initially characterize renal function of the cactus mouse, water consumption measurements and electrophysical dehydration effects for this species have also recently been documented [34]. Because the renal mechanisms for mitigating renal water-loss in $P$. eremicus have not been determined, a comparative genetic approach may be instrumental for characterizing this species' adaptive kidney phenotype. To this end, MacManes and Eisen [41] conducted a comparative analysis to find genes expressed in the kidney tissue of cactus mouse that were under positive selection relative to other mammals. MacManes [35] also recently conducted differential gene expression analyses on cactus mouse kidneys subjected to acute dehydration to explore transcriptomic renal responses. However, the transcriptomic resources available for this species extend considerably beyond renal tissue; transcripts from cactus mouse (as well as numerous other Peromyscus species) have been heavily utilized to pursue questions related to multiple aspects of evolutionary biology (reviewed in [5, 7]). Current investigations into cactus mouse desert-adaptive renal physiology include transcriptomic analyses [35]; however, we extended this genetic approach by shifting the focus from adaptions for survival to include physiological adaptations for reproductive success [33]. The cactus mouse is an ideal system for investigating dehydration effects on reproduction, as well as potential reproductive adaptations for drought, given decades of study of reproductive biology, as well as the more recent development of transcriptomic resources that include male reproductive tissues.

Substantial research has been done on the effects of various types of stress on reproduction (e.g. [14, 42-44]); furthermore, the impacts of dehydration stress on reproduction in desert specialized rodents have been historically explored by studies documenting the impacts of water availability as a reproductive cue (reviewed in $[45,46])$. Specifically, some female desert rodents have shown evidence of reproductive attenuation due to waterlimitation (Mongolian gerbil: [47]; hopping mouse: [48]), and male Mongolian gerbils subject to dehydration had decreased reproductive tissue mass [47]. In contrast, Shaw's jird, an Egyptian desert rodent, did not elicit perceivable reproductive response to water deprivation in either males or females [49]. Furthermore, watersupplementation studies among wild desert rodents 
resulted in prolonged breeding seasons in the hairyfooted gerbil and the four-striped grass mouse, but not in the Cape short-eared gerbil [50]. Recent research has confirmed the importance of rainfall as a reproductive cue in the Arabian spiny mouse [51], the Baluchistan gerbil [52], Chessman's gerbil [53] and the Spinifex hopping mouse [54]. The focus of this previous research was to investigate reproductive cues and consequences of water-limitation in desert rodents, namely how species have adapted breeding onset and cessation patterns to respond to water availability. Our current study experimentally tests reproductive responses to acute dehydration using a differential gene expression approach in the cactus mouse, which has not been previously evaluated for reproductive impacts of dehydration.

In nature, wild cactus mice are subjected to both acute and chronic dehydration, and understanding the reproductive effects of dehydration stress is an initial step towards fully characterizing the suite of phenotypes enabling their successful reproduction. Given that this species has evolved in southwestern United States deserts and that it breeds continuously throughout the year $[38,39]$, we predicted that neither acute nor chronic water stress, while physiologically demanding, would be associated with reproductive suppression. To evaluate acute water stress reproductive tissue gene expression responses in the current study, we leveraged previous research that characterized the transcriptome of male $P$. eremicus reproductive tissues from functional and comparative perspectives [33]. We extended upon this work by performing an RNAseq experiment to identify differentially expressed genes in testes between male $P$. eremicus subjected to acute dehydration versus control (fully hydrated) animals in order to determine the impacts, if any, on male reproduction. We hypothesized that male cactus mice would exhibit minimal gene expression level reproductive responses to acute dehydration because they are highly desert-adapted and they breed year-round, including in times of chronic draught. Specifically, we predicted that genes linked to reproductive function would not be differentially expressed in the testes in response to acute dehydration. We pursued this line of research on the effects of dehydration on reproduction in the cactus mouse in order to begin to address the need for additional studies focusing on physiological adaptations related to reproductive success in animals living in extreme and changing environments.

\section{Methods}

\section{Treatment groups, sample preparation and mRNA} sequencing

The cactus mice used for this study include only captive born individuals purchased from the Peromyscus Genetic Stock Center (Columbia, South Carolina). The animals at the stock center are descendant from individuals originally collected from a hot-desert location in Arizona more than 30 years ago. The colony used in this study has been housed since 2013 at the University of New Hampshire in conditions that mimic temperature and humidity levels in southwestern US deserts, as described previously [33]. Males and females are housed together, which provides olfactory cues to support reproductive maturation. Males do not undergo seasonal testicular atrophy, as indicated by successful reproduction throughout the year. The individuals used in this study were all of the same developmental stage - reproductively mature - which was assessed by observing that the testes had descended into the scrotum from the abdomen, making them visible.

Males that had free access to water prior to euthanasia are labeled as WET mice in our analyses. Mice that were water deprived, which we refer to as DRY mice, were weighed and then water deprived for $\sim 72 \mathrm{~h}$ directly prior to euthanasia. All mice were weighed prior to sacrifice, and DRY mice were evaluated for weight loss during dehydration. Individuals in the study were collected between September 2014 - April 2016.

Cactus mice were sacrificed via isoflurane overdose and decapitation in accordance with University of New Hampshire Animal Care and Use Committee guidelines (protocol number 130902) and guidelines established by the American Society of Mammalogists [55]. Trunk blood samples were collected following decapitation for serum electrolyte analyses with an Abaxis Vetscan VS2 using critical care cartridges (Abaxis). The complete methodology and results of the electrolyte study, as well as the reported measures of water consumption and weight loss due to dehydration are described fully elsewhere [34]. Rather, this study focused on differential gene expression between the testes of 11 WET and 11 DRY mice. Testes were harvested within ten minutes of euthanasia, placed in RNAlater (Ambion Life Technologies), flash-frozen in liquid nitrogen, and stored at $-80^{\circ}$ degree Celsius. A TRIzol chloroform protocol was implemented for RNA extraction (Ambion Life Technologies). Finally, the quantity and quality of the RNA product was evaluated with both a Qubit 2.0 Fluorometer (Invitrogen) and a Tapestation 2200 (Agilent Technologies, Palo Alto, USA).

Libraries were made with a TruSeq Stranded mRNA Sample Prep LT Kit (Illumina), and the quality and quantity of the resultant sequencing libraries were confirmed with the Qubit and Tapestation. Each sample was ligated with a unique adapter for identification in multiplex single lane sequencing. We submitted the multiplexed samples of the libraries for processing on lanes at the New York Genome Center Sequencing Facility (NY, New York). Paired - end sequencing reads of length 
125 bp were generated on an Illumina 2500 platform. Reads were parsed by individual samples according to their unique hexamer IDs in preparation for analysis.

\section{Assembly of testes transcriptome}

We assembled a testes transcriptome from a single reproductively mature male using the de novo transcriptome protocol described previously [56]. The testes transcripts were assembled with alternative methodologies utilizing several optimization procedures to produce a high-quality transcriptome; however, the permutations of this assembly process are described extensively elsewhere $[33,56]$. The testes transcriptome we selected was constructed as described below. The raw reads were error corrected using Rcorrector version 1.0.1 [57], then subjected to quality trimming (using a threshold of PHRED <2, as per [58]) and adapter removal using Skewer version 0.1.127 [59]. These reads were then assembled in the de novo transcriptome assembler BinPacker version 1.0 [60]. We also reduced sequence redundancy to improve the assembly using the sequence clustering software CD-HIT-EST version 4.6 [61, 62]. We further optimized the assembly with Transrate version 1.0.1 [63] by retaining only highly supported contigs (cutoff: 0.02847). We then evaluated the assembly's structural integrity with Transrate and assessed completeness using the vertebrata database in BUSCO version $1.1 \mathrm{~b} 1$ [64]. We quasimapped the raw reads to the assembly with Salmon version 0.7.2 [65] to confirm that mapping rates were high. Finally, the assembly was also annotated in dammit version 0.3.2, which finds open reading frames with TransDecoder and uses five databases (Rfam, Pfam, OrthoDB, BUSCO, and Uniref90) to thoroughly annotate transcripts (https://github.com/ camillescott/dammit).

\section{Differential gene and transcript expression analyses}

Several recent studies have critically evaluated alternative methodologies for differential transcript and gene expression to determine the relative merits of these approaches [66-69]. Soneson et al. [69] demonstrated that differential gene expression (DGE) analyses produce more accurate results than differential transcript expression (DTE) analyses. Furthermore, the differential gene expression approach is more appropriate than differential transcript expression for the scope of our research question, which is true of many evolutionary genomic studies [69]. However, because both DTE and DGE approaches are widespread in current literature, we deemed it important to confirm that these methodologies yielded concordant results in the current study.

We utilized edgeR [70, 71] as our primary statistical software because Schurch et al. [68] rigorously tested various packages for analyzing DGE, and edgeR performed optimally within our sample size range. While edge $R$ is a widely used statistical package for evaluating differential expression, we also confirmed our results with another popular package, DESeq2 [72], in order to validate our findings.

We performed differential expression analyses with three alternative methodologies. Two analyses were conducted in $\mathrm{R}$ version 3.3.1 [73] using edge $\mathrm{R}$ version 3.16.1, a Bioconductor package (release 3.4) that evaluates statistical differences in count data between treatment groups [70, 71]. Our first method utilized tximport, an R package developed by Soneson et al. [67], which incorporates transcriptome mapping-rate estimates with a gene count matrix to enable downstream DGE analysis. The authors assert that such transcriptome mapping can generate more accurate estimates of DGE than traditional pipelines [69]. While our first methodology evaluated differential gene expression, our second analysis used the transcriptome mapped read sets to perform differential transcript expression and identify the corresponding gene matches. The purpose of this second analysis was to evaluate whether the transcript expression results coincided with the gene expression results produced by the same program, edgeR. Finally, our third methodology determined differential gene expression with tximport in conjunction with DESeq2 version 1.14.0 [72], a Bioconductor package (release 3.4) which also evaluates statistical differences in expression. We performed this alternative DGE analysis with DESeq2 in order to corroborate our DGE results from edgeR. Thus, the results for all three differential expression analyses were evaluated to determine the coincidence among the genes identified as significantly different between the WET and DRY groups. These alternative differential expression methods are described in detail below.

We quasimapped each of the 11 WET and 11 DRY sample read sets to the testes transcriptome with Salmon version 0.7.2 to generate transcript count data. To perform the gene-level analysis in edgeR, we constructed a gene ID to transcript ID mapping file, which was generated by a BLASTn [74, 75] search for matches in the Mus musculus transcriptome (http://www.ensem bl.org/index.html) version 7/11/16 release-85. We then imported the Salmon-generated count data and the gene ID to transcript ID mapping file into $\mathrm{R}$ using the tximport package [69] to convert the transcript count data into gene counts. This gene count data was imported into edgeR for differential gene expression analysis [70,71]. We applied TMM normalization to the data, calculated common and tagwise dispersions, and performed exact tests $(p<0.05)$ adjusting for multiple comparisons with the Benjamini-Hochburg correction [76] to find differentially expressed genes, which we identified in Ensembl (http://www.ensembl.org/index.html). 
Next, we performed a transcript-level analysis using edgeR. To accomplish this, the Salmon-generated count data was imported into $\mathrm{R}$ and analyzed as was described above for the gene-level analysis in edgeR. After determining which transcript IDs were differentially expressed, we identified the corresponding genes using the gene ID to transcript ID matrix described previously. The significantly expressed transcripts without corresponding gene matches were selected for an additional BLASTn search in the NCBI non-redundant nucleotide database (http://blast.ncbi.nlm.nih.gov/Blast.cgi). However, these results were not subjected to any additional analyses, because these matches were not consistent across all three differential expression analyses. The location of this list of BLASTn search matches is provided in Additional file 1.

The third analysis used DESeq2 to conduct an additional gene-level test, using the same methods as described for the previous gene-level analysis, with the exception that data were imported into an alternative software package. We determined the significantly differentially expressed genes $(p<0.05)$ based on normalized counts and using the Benjamini-Hochburg correction [76] for multiple comparisons. We only retained genes with a $-1<\log _{2}$ fold change $>1$ in order to filter genes at a conservative threshold for differential expression based on our sample size [68]. This filtering was not necessary for either of the edgeR analyses because $\log _{2}$ fold changes exceeded this threshold for the differentially expressed genes and transcripts $\left(-1.3<\log _{2}\right.$ fold change $>1.4$, in all cases).

We also compared the $\log _{2}$ fold change values (of treatment differences by mapped count) for each gene from the edgeR and DESeq2 gene-level analyses in a linear regression. This statistical test was performed in order to evaluate the degree of concordance between the two DGE analyses. Furthermore, we constructed a list of genes identified as differentially expressed by all three analyses, which were further evaluated for function as well as chromosomal location. These genes were also explored in STRING version 10.0 (http://string-db.org) to determine their protein-protein interactions [77, 78].

We also evaluated overall patterns of expression for all genes analyzed using DGE in edgeR. Specifically, we correlated median expression levels (normalized cpms) of each gene for the WET and DRY treatments. We also determined which genes were relatively more highly expressed by treatment without restricting by significance (calculated by: DRY cpm/WET cpm). The resulting list of genes with higher relative expression in DRY mice and the list of genes with higher relative expression in WET mice were imported into PANTHER (http:// pantherdb.org: [79, 80]) for gene ontology analyses. Firstly, we compared the PANTHER GO-Slim Molecular Function patterns of both gene sets. Then we performed a PANTHER Overrepresentation Test (PANTHER version 11.1, released 2016-10-24) for the relatively high DRY expression gene list analyzed against the high WET expression gene list as the reference list. The GO significance results reported were Bonferroni corrected for multiple comparisons.

Lastly, we performed an a priori test for DGE in edgeR on a small subset of nine genes encoding hormones and hormone receptors known to be involved in various aspects of reproductive functionality in male rodents. These genes are: steroidogenic acute regulatory protein (StAR), prolactin receptor (Prlr), luteinizing hormone/choriogonadotropin receptor (Lhgcr), inhibin (Inha), ghrelin (Ghrl), estrogen related receptor gamma (Essrg), estrogen related receptor alpha (Essra), androgen receptor (Ar), and activin receptor type-2A (Acvr2a). We retrieved the Mus musculus genomic sequences for these hormones and receptors from Ensembl (release 88: March 2017) and then executed BLASTn searches for the corresponding Peromyscus eremicus sequences in the testes transcriptome. The Ensembl gene identifiers (Mus musculus) corresponding to the $P$. eremicus transcripts were queried from the table of results produced by the edgeR DGE analysis to evaluate treatment differences in expression.

\section{Results}

\section{Data and code availability}

The testes transcriptome was assembled from a 45.8 million paired read data set. Additionally, there were 9-20 million paired reads for each of the 22 testes data sets used for the differential expression analysis (Additional file 2: Table S1), yielding 304,466,486 reads total for this analysis. The raw reads are available at the European Nucleotide Archive under study accession number PRJEB18655. All data files, including the testes un-annotated transcriptome, the dammit annotated transcriptome, and the data generated by the differential gene expression analysis (described below) are available on Dryad (doi:10.5061/ dryad.743p5). All code for these analyses is also posted on Dryad (doi:10.5061/dryad.743p5).

\section{Assembly of testes transcriptome}

The performance of multiple transcriptome assemblies was evaluated thoroughly, and the selected optimized testes assembly met high quality and completeness standards, and it also contains relatively few contigs and has high read mapping rates (Table 1). Therefore, this transcriptome was used for our differential expression analyses. The transcriptome was also annotated, and the complete statistics for this dammit annotation are provided in Table 1. 
Table 1 Transcriptome assembly (BinPacker CD-hit-est Transrate Corrected) performance metrics for: contig number, TransRate score (Score), BUSCO indices: \% single copy orthologs (\% SCO), \% duplicated copy orthologs (\% DCO), \% fragmented (\% frag), and \% missing (\% miss), as well as Salmon mapping rates (\% mapping) for the optimized testes assembly. Dammit transcriptome assembly annotation statistics, including searches in the program TransDecoder for open reading frames (ORFs) and searches for homologous sequences in five databases: Rfam, Pfam-A, Uniref90, OrthoDB, and BUSCO. Percentages were calculated from the count number of each parameter divided by the total number of contigs in the transcriptome $(155,134)$. The only exception to this calculation is for complete ORFs, which were calculated as a percentage of the total ORFs $(75,482)$. The BUSCO results for the annotated assembly are not shown here as they are identical to those for the un-annotated assembly

\begin{tabular}{|c|c|c|c|c|c|c|c|}
\hline \multicolumn{8}{|c|}{ Transcriptome Assembly Statistics } \\
\hline Contig \# & Score & $\%$ SCO & $\%$ DCO & $\%$ frag & $\%$ miss & \multicolumn{2}{|l|}{ \% mapping } \\
\hline 155,134 & 0.335 & 77 & 27 & 5.9 & 16 & \multicolumn{2}{|l|}{92.14} \\
\hline \multicolumn{8}{|c|}{ Dammit Annotation Statistics } \\
\hline Search Type & TransDecode & & Rfam & Pfam-A & Uniref90 & OrthoDB & Dammit \\
\hline Parameter & Total ORFs & Complete ORFs & ncRNAs & Protein Domains & Proteins & Orthologs & Total Annotated Contigs \\
\hline Count & 75,482 & 43,028 & 937 & 25,675 & 62,865 & 51,806 & 77,915 \\
\hline Percentage & $48.7 \%$ & $57.0 \%$ & $0.6 \%$ & $16.6 \%$ & $40.5 \%$ & $33.4 \%$ & $50.2 \%$ \\
\hline
\end{tabular}

\section{Differential gene and transcript expression analyses}

Salmon quasimapping rates of all read datasets to the assembly were sufficiently high (range: $81.46-87.02 \%$; mean ${ }_{\text {WET }}=84.41$; mean ${ }_{\mathrm{DRY}}=83.81$; Additional file 2: Table S1), indicating the successful generation of transcript count data for our differential expression analyses. The exact test performed for our gene-level analysis in edgeR indicated that fifteen genes reached statistical significance (after adjusting for multiple comparisons) for DGE between the WET and DRY treatment groups (Additional file 3: Figure S1). Specifically, seven genes were more highly expressed in WET individuals, and eight genes were more highly expressed in DRY individuals (Table 2).

We also performed an alternative transcript-level analysis using the referenced transcriptome mapped reads exclusively with edgeR. The exact test found 66 differentially expressed transcripts (Additional file 4: Figure S2), 45 of which were more highly expressed in the WET group, and 21 were more highly expressed in the DRY group (Table 3). Ten of these differentially expressed transcripts were consistent with differentially expressed genes from the edgeR DGE analysis. In addition, the significantly expressed transcripts without an Ensembl ID match (nine WET and nine DRY) were retrieved for performing an nt all species BLASTn search (http:// blast.ncbi.nlm.nih.gov/Blast.cgi), and the file location for these results are in the Additional file 1.

The gene-level analysis conducted in DESeq2 yielded 215 significantly differentially expressed genes (Additional file 5: Figure S3), 67 of which were more highly expressed in the WET group, while 148 were more highly expressed in the DRY group. However, only 20 of these genes remained when we filtered them with a $-1<\log _{2}$ fold change $>1$ to retain genes with a conservative threshold difference between treatment groups. This list of 20 genes yielded 16 genes more highly expressed in WET mice and four genes highly expressed in DRY mice (Table 4). Nine of these genes overlapped with those found to be significant in the previous two edgeR analyses.

To evaluate the correlation of $\log _{2}$ fold change results for each gene (Ensembl ID) from the two DGE analyses (EdgeR and DESeq2), we performed a regression of

Table 2 EdgeR determined significantly differentially expressed genes by treatment group in $P$. eremicus testes. Of the 15 DGE, seven were significantly more highly expressed in WET mice (High in WET) and eight were more highly expressed in DRY mice (High in DRY)

\begin{tabular}{llllll}
\hline Ensembl ID & $\log _{2}$ FC & logCPM & FDR & Gene ID & HIGH \\
\hline ENSMUSG00000079019.2 & -4.354 & 1.650 & $5.82 E-09$ & Insl3 & WET \\
ENSMUSG00000054200.6 & -3.734 & 0.619 & $1.82 E-06$ & Ffar4 & WET \\
ENSMUSG00000026435.15 & -2.448 & 2.447 & $1.13 E-03$ & Slc45a3 & WET \\
ENSMUSG00000025020.11 & -2.231 & 1.770 & $1.13 E-03$ & Slit1 & WET \\
ENSMUSG00000031170.14 & -2.421 & 2.578 & $1.13 E-03$ & Slc38a5 & WET \\
ENSMUSG00000030830.18 & -2.180 & 1.666 & $3.37 E-02$ & Itgal & WET \\
ENSMUSG00000032554.15 & -2.066 & 3.287 & $4.85 E-02$ & Trf & WET \\
ENSMUSG00000001768.15 & 3.086 & 1.006 & $1.46 E-07$ & Rin2 & DRY \\
ENSMUSG00000025479.9 & 2.971 & 3.001 & $7.97 E-05$ & Cyp2e1 & DRY \\
ENSMUSG00000020427.11 & 2.681 & 3.887 & $1.13 E-03$ & Igfbp3 & DRY \\
ENSMUSG00000019997.11 & 2.314 & 3.235 & $1.13 E-03$ & Ctgf & DRY \\
ENSMUSG00000040170.13 & 1.951 & 0.753 & $1.72 E-03$ & Fmo2 & DRY \\
ENSMUSG00000023915.4 & 1.534 & 1.290 & $2.02 E-02$ & Tnfrsf21 & DRY \\
ENSMUSG00000052974.8 & 2.077 & 0.647 & $2.26 E-02$ & Cyp2f2 & DRY \\
ENSMUSG00000027901.12 & 2.492 & -0.620 & $4.78 E-02$ & Dennd2d & DRY \\
\hline
\end{tabular}


Table 3 EdgeR determined significantly differentially expressed transcripts by treatment group in P. eremicus testes. Of the 66 total DTE, 45 were significantly more highly expressed in WET mice (High in WET) and 21 were more highly expressed in DRY mice (High in DRY). BLASTn matches to Ensembl IDs and corresponding Gene IDs are provided (Gene)

\begin{tabular}{|c|c|c|c|c|c|}
\hline Transcript ID & $\log _{2} \mathrm{FC}$ & $\log C P M$ & FDR & Ensembl ID & Gene \\
\hline \multicolumn{6}{|l|}{ HIGH: WET } \\
\hline BINPACKER.15365.1 & -3.703 & 0.047 & $5.31 \mathrm{E}-11$ & ENSMUSG00000054200.6 & Ffar4 \\
\hline BINPACKER.2960.1 & -4.268 & 1.147 & 2.06E-09 & ENSMUSG00000079019.2 & Insl3 \\
\hline BINPACKER.17981.2 & -2.975 & 0.436 & $6.29 \mathrm{E}-08$ & ENSMUSG00000026435.15 & Slc45a3 \\
\hline BINPACKER.9961.2 & -2.426 & 1.998 & 7.50E-07 & ENSMUSG00000031170.14 & Slc38a5 \\
\hline BINPACKER.3452.1 & -2.507 & -0.140 & $3.56 \mathrm{E}-06$ & no match & - \\
\hline BINPACKER.724.4 & -2.162 & 2.667 & $8.32 \mathrm{E}-06$ & ENSMUSG00000032554.15 & Trf \\
\hline BINPACKER.9604.1 & -2.582 & 0.547 & 7.87E-05 & no match & - \\
\hline BINPACKER.31087.1 & -2.908 & -0.858 & 9.74E-05 & no match & - \\
\hline BINPACKER.24398.1 & -2.440 & -0.689 & $9.74 \mathrm{E}-05$ & ENSMUSG00000036596.6 & $\mathrm{Cpz}$ \\
\hline BINPACKER.9726.1 & -3.474 & -0.107 & $2.38 \mathrm{E}-04$ & ENSMUSG00000026435.15 & Slc45a3 \\
\hline BINPACKER. 9218.3 & -1.578 & 1.525 & $2.76 \mathrm{E}-04$ & ENSMUSG00000021253.6 & Tgfb3 \\
\hline BINPACKER.18534.1 & -2.332 & 1.346 & $4.85 \mathrm{E}-04$ & ENSMUSG00000025020.11 & Slit1 \\
\hline BINPACKER.17022.3 & -2.899 & -0.561 & $1.00 \mathrm{E}-03$ & no match & - \\
\hline BINPACKER.13806.1 & -2.442 & -0.381 & $1.13 \mathrm{E}-03$ & ENSMUSG00000025172.2 & Ankrd2 \\
\hline BINPACKER.7740.1 & -2.790 & 1.095 & $1.13 \mathrm{E}-03$ & ENSMUSG00000057074.6 & Ces1g \\
\hline BINPACKER.10034.2 & -4.420 & 0.387 & $1.23 \mathrm{E}-03$ & ENSMUSG00000026516.8 & $\mathrm{Nvl}$ \\
\hline BINPACKER.11560.2 & -1.465 & 2.050 & $1.66 \mathrm{E}-03$ & ENSMUSG00000021913.7 & Ogdhl \\
\hline BINPACKER.13701.1 & -1.312 & 1.804 & $2.28 \mathrm{E}-03$ & ENSMUSG00000025648.17 & Pfkfb4 \\
\hline BINPACKER.3510.3 & -2.163 & 0.906 & $2.95 \mathrm{E}-03$ & ENSMUSG00000027822.16 & Slc33a1 \\
\hline BINPACKER.15806.1 & -1.700 & 1.062 & 3.39E-03 & ENSMUSG00000015702.13 & Anxa9 \\
\hline BINPACKER.17992.1 & -2.542 & 0.653 & 3.39E-03 & ENSMUSG00000030830.18 & Itgal \\
\hline BINPACKER.9726.2 & -2.119 & 0.560 & $3.48 \mathrm{E}-03$ & ENSMUSG00000026435.15 & Slc45a3 \\
\hline BINPACKER.6383.3 & -2.093 & 1.270 & 4.16E-03 & ENSMUSG00000002109.14 & Ddb2 \\
\hline BINPACKER.20716.2 & -4.204 & -0.566 & $5.75 \mathrm{E}-03$ & ENSMUSG00000013846.9 & St 3 gal1 \\
\hline BINPACKER.20114.1 & -1.661 & 0.501 & 5.97E-03 & ENSMUSG00000030972.6 & Acsm5 \\
\hline BINPACKER.18622.1 & -1.645 & 1.704 & $6.36 \mathrm{E}-03$ & no match & - \\
\hline BINPACKER.24914.1 & -2.211 & -0.159 & $9.83 \mathrm{E}-03$ & ENSMUSG00000003555.7 & Cyp17a1 \\
\hline BINPACKER.31815.1 & -1.905 & -0.770 & 9.83E-03 & no match & - \\
\hline BINPACKER.6740.3 & -3.090 & -0.434 & $1.04 \mathrm{E}-02$ & no match & - \\
\hline BINPACKER.20530.1 & -1.626 & 0.545 & $1.12 \mathrm{E}-02$ & ENSMUSG00000038463.8 & Olfml2b \\
\hline BINPACKER.20656.1 & -1.910 & -0.531 & $1.22 \mathrm{E}-02$ & ENSMUSG00000029373.7 & Pf4 \\
\hline BINPACKER.4855.1 & -1.340 & 4.025 & $1.23 \mathrm{E}-02$ & ENSMUSG00000059991.7 & Nptx2 \\
\hline BINPACKER.1846.1 & -3.280 & -0.792 & $1.23 \mathrm{E}-02$ & no match & - \\
\hline BINPACKER.6494.2 & -3.363 & 0.029 & $1.26 \mathrm{E}-02$ & ENSMUSG00000052861.13 & Dnah6 \\
\hline BINPACKER.1818.1 & -1.713 & 3.289 & 2.03E-02 & ENSMUSG00000024125.1 & Sbpl \\
\hline BINPACKER.10743.2 & -1.915 & -0.525 & 2.06E-02 & ENSMUSG00000041607.16 & Mbp \\
\hline BINPACKER.13054.2 & -1.147 & 2.697 & $2.06 \mathrm{E}-02$ & ENSMUSG00000022994.8 & Adcy6 \\
\hline BINPACKER.6807.1 & -1.330 & 2.106 & $2.13 \mathrm{E}-02$ & ENSMUSG00000046687.5 & Gm5424 \\
\hline BINPACKER.14160.1 & -2.051 & 0.603 & $2.86 \mathrm{E}-02$ & ENSMUSG00000041556.8 & $\mathrm{FbxO2}$ \\
\hline BINPACKER.16191.1 & -1.431 & 0.926 & $3.42 \mathrm{E}-02$ & ENSMUSG00000028654.13 & $\mathrm{Mycl}$ \\
\hline BINPACKER.10141.3 & -3.283 & -1.191 & $3.68 \mathrm{E}-02$ & ENSMUSG00000024132.5 & Eci1 \\
\hline
\end{tabular}


Table 3 EdgeR determined significantly differentially expressed transcripts by treatment group in P. eremicus testes. Of the 66 total DTE, 45 were significantly more highly expressed in WET mice (High in WET) and 21 were more highly expressed in DRY mice (High in DRY). BLASTn matches to Ensembl IDs and corresponding Gene IDs are provided (Gene) (Continued)

\begin{tabular}{|c|c|c|c|c|c|}
\hline BINPACKER.23790.1 & -1.756 & -0.275 & 4.51E-02 & ENSMUSG00000001119.7 & Col6a1 \\
\hline BINPACKER.22521.1 & -1.841 & -0.056 & 4.52E-02 & ENSMUSG00000054083.8 & Capn12 \\
\hline BINPACKER.1061.6 & -1.807 & 1.943 & 4.93E-02 & no match & - \\
\hline BINPACKER.17734.1 & -1.660 & 2.109 & 4.94E-02 & ENSMUSG00000049608.8 & Gpr55 \\
\hline \multicolumn{6}{|l|}{ HIGH: DRY } \\
\hline BINPACKER.21794.1 & 2.434 & 3.117 & 4.41E-08 & ENSMUSG00000020427.11 & Igfbp3 \\
\hline BINPACKER.28731.1 & 2.484 & 1.634 & 4.41E-08 & no match & - \\
\hline BINPACKER.5662.4 & 2.061 & 2.419 & $1.32 \mathrm{E}-07$ & ENSMUSG00000019997.11 & Ctgf \\
\hline BINPACKER.87639.1 & 2.682 & 0.345 & $1.96 \mathrm{E}-07$ & ENSMUSG00000001768.15 & $\operatorname{Rin} 2$ \\
\hline BINPACKER.35470.1 & 2.367 & 1.786 & 1.89E-04 & no match & - \\
\hline BINPACKER.52106.1 & 2.096 & -0.542 & $6.83 \mathrm{E}-04$ & no match & - \\
\hline BINPACKER.3957.3 & 6.309 & 1.579 & $1.02 \mathrm{E}-03$ & ENSMUSG00000019988.6 & Nedd1 \\
\hline BINPACKER.116235.1 & 2.212 & 0.301 & 3.94E-03 & no match & - \\
\hline BINPACKER.4449.4 & 3.428 & -0.538 & $6.74 \mathrm{E}-03$ & ENSMUSG00000005150.16 & Wdr83 \\
\hline BINPACKER.28.2 & 4.183 & 2.295 & 1.05E-02 & ENSMUSG00000075706.10 & Gpx4 \\
\hline BINPACKER.56553.1 & 1.472 & 0.172 & $1.46 \mathrm{E}-02$ & no match & - \\
\hline BINPACKER.93518.1 & 1.711 & -0.793 & 1.57E-02 & no match & - \\
\hline BINPACKER.11512.1 & 1.187 & 3.654 & 1.70E-02 & ENSMUSG00000031591.14 & Asah1 \\
\hline BINPACKER.66588.1 & 1.851 & -0.347 & $1.71 \mathrm{E}-02$ & no match & - \\
\hline BINPACKER.42718.1 & 1.542 & 0.507 & 2.06E-02 & ENSMUSG00000030790.15 & Adm \\
\hline BINPACKER.49203.1 & 1.639 & -0.035 & 2.44E-02 & no match & - \\
\hline BINPACKER.147548.1 & 1.744 & -0.007 & 2.99E-02 & ENSMUSG00000042757.15 & Tmem108 \\
\hline BINPACKER.23756.2 & 1.265 & 3.468 & $3.01 \mathrm{E}-02$ & ENSMUSG00000022061.8 & Nkx3-1 \\
\hline BINPACKER.12709.1 & 3.906 & 2.611 & 3.01E-02 & ENSMUSG00000028639.14 & Ybx1 \\
\hline BINPACKER.5280.2 & 3.874 & 0.257 & $3.76 \mathrm{E}-02$ & ENSMUSG00000074582.10 & Arfgef2 \\
\hline BINPACKER.58702.1 & 1.780 & -0.500 & 4.93E-02 & no match & - \\
\hline
\end{tabular}

these $\log$ values, and they were significantly correlated (Fig. 1: Adj- ${ }^{2}=0.6596 ; F(1,14,214)=2.754 \times 10^{4}$; $\left.p<2.2 \times 10^{-16}\right)$. This further demonstrates the concordance of the DGE analyses in these two software packages.

To evaluate the degree to which the three analyses produced concordant results, we generated a list of genes which were found to be significantly differently expressed by treatment across all three analyses (Additional file 6 : Table S2). There were six genes that were consistently highly-expressed in the WET group and three genes that were highly-expressed in the DRY group. The six highlyexpressed WET genes are Insulin-like 3 (Insl3), Free-fatty acid receptor 4 (Ffar4), Solute carrier family 45 member 3 (Slc45a3), Solute carrier family 38 member 5 (Slc38a5), Integrin alpha L (Itgal), and Transferrin (Trf). The three highly-expressed DRY genes are Ras and Rab Interactor 2 (Rin2), Insulin-like growth factory binding protein 3 (Igfbp3), and Connective tissue growth factor (Ctgf). Because the patterns of expression of these nine genes were corroborated by multiple methodologies, we are confident that they are differentially expressed between our treatments. Estimates of expression for these genes generated using the gene-level edge $\mathrm{R}$ analysis are plotted in Fig. 2.

The significantly differently expressed genes were evaluated for gene function and chromosomal location (Table 5). These genes occur throughout the genome; namely, they are located on different chromosomes. The diverse functions of each gene will be described below. In addition, we generated STRING diagrams (http:// string-db.org/) to view the protein-protein interactions for each of these nine genes [77, 78].

Slc38a5 and Slc45a3 are among the highly expressed genes in the WET group (they have lower expression in the DRY group); these two solute carriers are members of a large protein family that is responsible for crossmembrane solute transport (reviewed in [81-83]). Slc38a5 is involved in sodium-dependent amino-acid 
Table 4 DESeq2 determined significantly differentially expressed genes by treatment group in P. eremicus testes. Of the 20 DGE with a $-1<\log _{2}$ fold change $>1$, 16 were significantly more highly expressed in WET mice (High in WET) and four were more highly expressed in DRY mice (High in DRY)

\begin{tabular}{|c|c|c|c|c|c|}
\hline Ensembl ID & baseMean & $\log _{2} \mathrm{FC}$ & p-adjusted & Gene ID & $\mathrm{HIGH}$ \\
\hline ENSMUSG00000054200.6 & 8.77721485 & -2.2659204 & $1.24 \mathrm{E}-27$ & Ffar4 & WET \\
\hline ENSMUSG00000026435.15 & 38.7630267 & -2.2184407 & $1.16 \mathrm{E}-42$ & Slc45a3 & WET \\
\hline ENSMUSG00000079019.2 & 24.7158409 & -1.6454793 & $4.55 \mathrm{E}-13$ & Insl3 & WET \\
\hline ENSMUSG00000031170.14 & 42.2322119 & -1.6434261 & $6.64 \mathrm{E}-15$ & Slc38a5 & WET \\
\hline ENSMUSG00000038463.8 & 16.2605998 & -1.4619721 & $3.55 E-12$ & Olfml2b & WET \\
\hline ENSMUSG00000030830.18 & 22.0478661 & -1.4358002 & $3.41 \mathrm{E}-10$ & Itgal & WET \\
\hline ENSMUSG00000032554.15 & 67.5197473 & -1.3762549 & $7.26 \mathrm{E}-10$ & Trf & WET \\
\hline ENSMUSG00000021253.6 & 31.2493344 & -1.3551661 & $7.02 \mathrm{E}-14$ & Tgfb3 & WET \\
\hline ENSMUSG00000030972.6 & 13.8934534 & -1.1709964 & $2.37 \mathrm{E}-07$ & Acsm5 & WET \\
\hline ENSMUSG00000059991.7 & 173.025492 & -1.1528314 & $5.12 \mathrm{E}-11$ & Nptx2 & WET \\
\hline ENSMUSG00000046687.5 & 44.9527785 & -1.0989949 & 8.31E-09 & Gm5424 & WET \\
\hline ENSMUSG00000024125.1 & 101.5876 & -1.0962074 & 9.77E-06 & Sbpl & WET \\
\hline ENSMUSG00000021913.7 & 46.5401886 & -1.0876018 & $8.70 \mathrm{E}-07$ & Ogdhl & WET \\
\hline ENSMUSG00000015702.13 & 27.7002506 & -1.0603879 & $1.95 \mathrm{E}-05$ & Anxa9 & WET \\
\hline ENSMUSG00000036596.6 & 6.6698922 & -1.0243046 & $9.04 \mathrm{E}-05$ & $\mathrm{Cpz}$ & WET \\
\hline ENSMUSG00000025172.2 & 13.2622565 & -1.0138171 & 0.00013318 & Ankrd2 & WET \\
\hline ENSMUSG00000042757.15 & 14.5676529 & 1.00643936 & 0.00019556 & Tmem108 & DRY \\
\hline ENSMUSG00000019997.11 & 64.49614 & 1.03331405 & 7.67E-05 & Ctgf & DRY \\
\hline ENSMUSG00000020427.11 & 92.3763518 & 1.56656207 & 4.55E-13 & Igfbp3 & DRY \\
\hline ENSMUSG00000001768.15 & 12.3794312 & 1.72433255 & $8.16 \mathrm{E}-16$ & $\operatorname{Rin} 2$ & DRY \\
\hline
\end{tabular}

transport, while Slc45a3 is purported to transport sugars ([84, 85]; http://slc.bioparadigms.org/), thereby playing an important potential role in maintaining water balance via management of oncotic pressures. Slc38a5 (Fig. 3a) has interactions with multiple additional solute carriers, including Slc1A5, Slc36A2, Slc36A3, and Slc36A4. Slc38a5 also has an interaction with disintegrin and metalloproteinase domain-containing 7 (Adam7), which is involved in sperm maturation and the acrosome reaction [86]. In contrast, Slc45a3 (Fig. 3b) does not have known protein interactions with other solute carriers; however, this protein does interact with steroidogenic acute regulatory protein (StAR), which is critical in steroidogenesis [87]. Notably, our a priori DGE analysis did not demonstrate treatment differences in expression for StAR.

Insl3 was lower expressed in the DRY group, and this hormone purportedly regulates fertility in male and female mammals by preventing apoptosis of germ cells in reproductive organs of both sexes ([88-90]. In male rodents, Insl3 is critical to development by facilitating testicular descent, and it is also present in testes of adults, where it binds to relaxin family peptide receptor 2 (Rxfp2), also known as $\operatorname{Lrg} 8([88,88]$. Protein interaction data for Insl3 (Fig. 3c) indicate that this hormone interacts with Rxfp2 and Rxfp1, as well as other proteins, including leptin (Lep), a pleiotropic hormone involved in reproduction, immunity, and metabolism (reviewed in [91]).

Ffar4 was also down-regulated in the DRY group. Omega-3 fatty acid receptor 1 (O3Far1) is an alias of Ffar4, and it has roles in metabolism and inflammation [92]. This protein interacts with multiple other free fatty acid receptors and G-protein coupled receptors as well as Stanniocalcin 1 (Stc1) (Fig. 3d). Stc1 is involved in phosphate and calcium transportation [93]; however, this protein's functional role in mice remains enigmatic [94].

Another of the lower expressed DRY group genes is Itgal (also known as CDa11a), which has multifaceted roles in lymphocyte-mediated immune responses [95]. Concordantly, the protein interactions with Itgal (Fig. 3e) include numerous proteins integral to immunity, such as Intracellular adhesion molecules (specifically, ICAM1,2,4), which are expressed on the cell surface of immune cells and endothelial cells. Itgal is a receptor for these ICAM glycoproteins, which bind during immune system responses (reviewed in [96]). However, an additional role of intercellular adhesion molecules has been proposed in spermatogenesis, whereby ICAMs may be integral to transporting non-mobile developing sperm cells through the seminiferous epithelium [97]. 


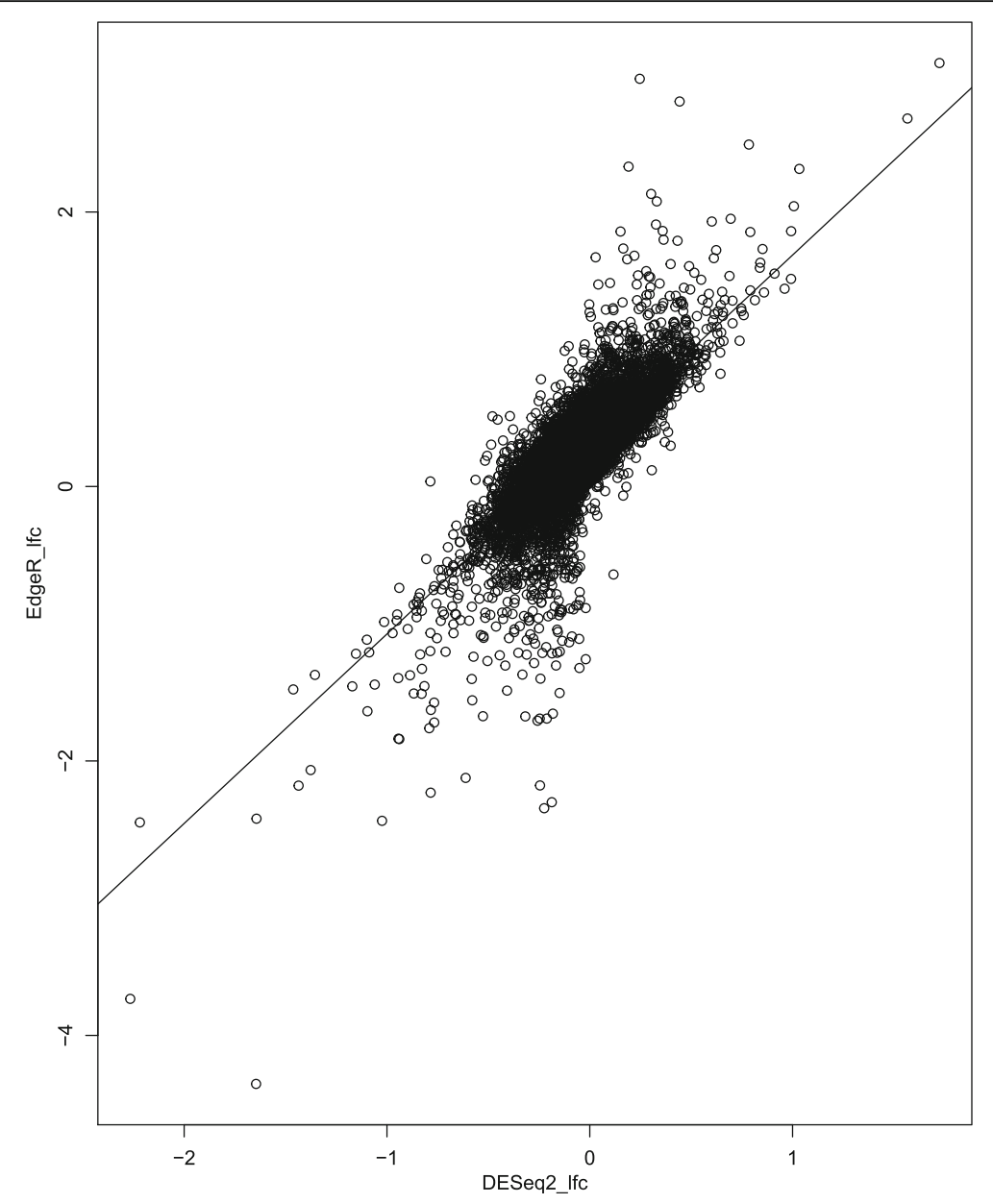

Fig. 1 Correlation of $\log _{2}$ fold change results for all Ensembl ID gene matches from DESeq2 and edgeR DGE analyses (Adj- $R^{2}=0.6596$; $\left.F(1,14,214)=2.754 \times 10^{4} ; p<2.2 \times 10^{-16}\right)$

The final gene with lower expression levels in the DRY treatment is Trf, which modulates the amount of freeiron in circulation and binds to transferrin receptors on the surface of erythrocyte precursors to deliver iron (reviewed in [98]). Trf interacts with multiple proteins (Fig. 3f) involved in iron transport and uptake, including Steap family member 3 (Steap3), hephaestin (Heph), cerulopslamin $(\mathrm{Cp})$, Solute carrier protein 40 member 1 (Slc40A1), and several H+ ATPases. Furthermore, Trf is linked to apolipoprotein A-1 (Apoa1), which interacts with immunoglobulin in a complex named sperm activating protein (Spap) to activate the motility of sperm when it inhabits the female genital tract $[99,100]$.

One of the highly expressed genes in the DRY group is Rin2, which is involved in endocytosis (reviewed in [101]) and membrane trafficking through its actions as an effector protein for the GTPases in the Rab family within the Ras superfamily (reviewed in [102]). Rin2 protein-protein interactions (Fig. 4a) include Ras related protein Rab5, which is involved in vesicle transport as well as vasopressin-regulated water reabsorption. This mechanism for water reabsorption via Aquaporin 2 (Aqp2) in the kidney has been thoroughly reviewed by Boone and Deen [103] and Kwon et al. [104].

The second gene highly expressed in the DRY group is Igfbp3, which modulates the effects of insulin growth factors. Thus, the protein directly interacts (Fig. 4b) with insulin growth factors 1 and 2 (Igf1, Igf2), which are responsible for increasing growth in most tissues (reviewed in [105]; [106]). Ctgf was also highly expressed in the DRY group, and this protein is responsible for increased fibrosis and extracellular matrix formation (Reviewed in [107]). The protein interactions for Ctgf (Fig. 4c) include many transcription activators in the Hippo signaling pathway, including multiple TEA domain transcription factors (Tead1, 2, 3 and 4), WW domain containing transcription regulator 1 (Wwtr1), as well as Yes-associated protein 1 (Yap1), which is responsible for both increasing apoptosis and preventing cell proliferation to mitigate tumor growth and control organ size (Reviewed in [108]). 


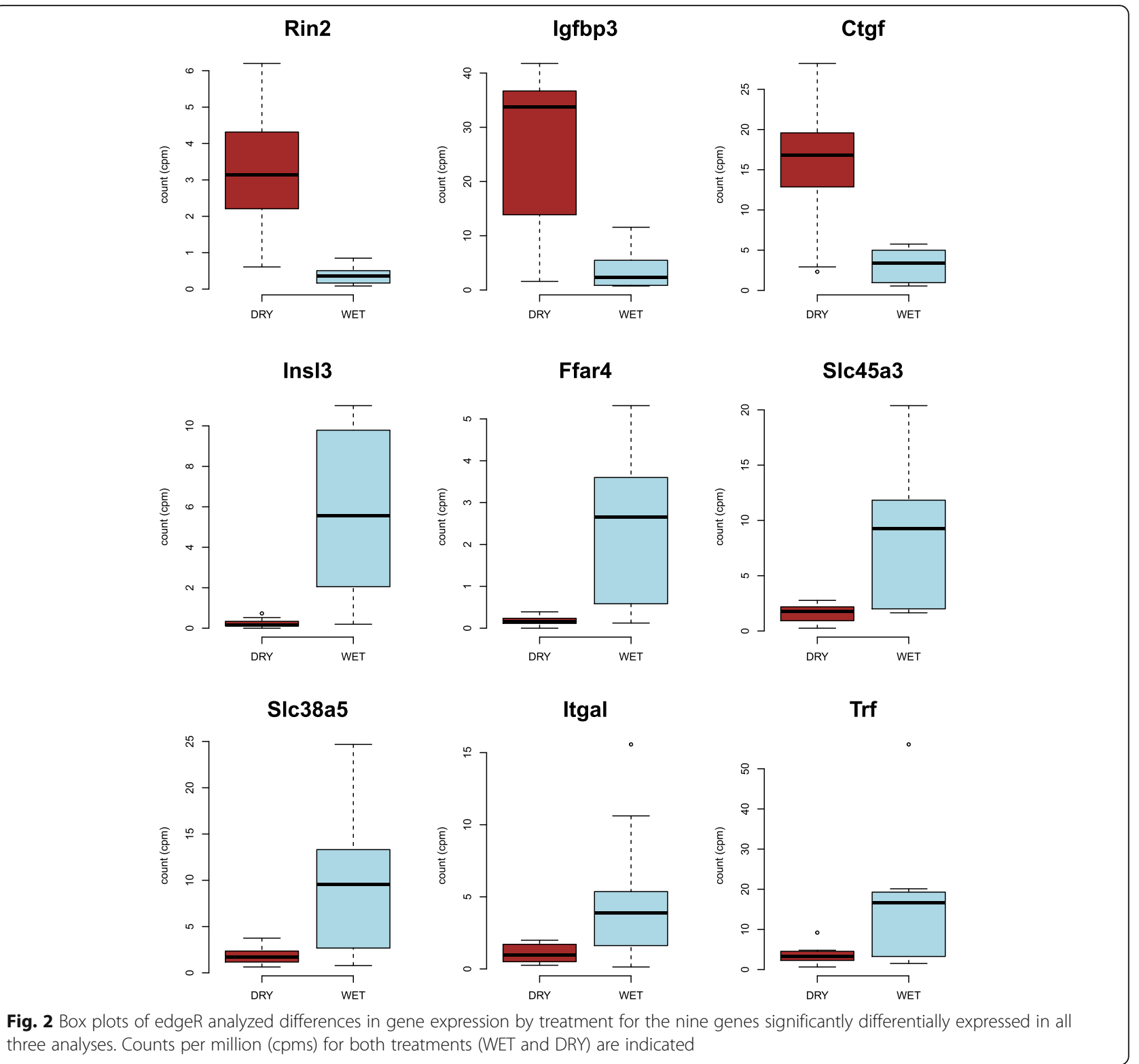

Table 5 Functional information and chromosome (CHR) locations (Mus musculus) for the nine genes differentially expressed across all three analyses in $P$. eremicus testes by treatment group

\begin{tabular}{|c|c|c|c|c|}
\hline Gene Name & Gene ID & Gene Function & $\mathrm{CHR}$ & $\mathrm{HIGH}$ \\
\hline Insulin-like 3 & Insl3 & testicular function and testicular development & 8 & WET \\
\hline Free-fatty acid receptor 4 & Ffar4 & metabolism and inflammation & 19 & WET \\
\hline Solute carrier family 45 member 3 & Slc45a3 & sugar transport & 1 & WET \\
\hline Solute carrier family 48 member 5 & Slc38a5 & sodium-dependent amino acid transport & $x$ & WET \\
\hline Integrin alpha L & Itgal & lymphocyte-mediated immune responses & 7 & WET \\
\hline Transferrin & Trf & iron transport and delivery to erythrocytes & 9 & WET \\
\hline Ras and Rab Interactor 2 & $\operatorname{Rin} 2$ & endocytosis and membrane trafficking & 2 & DRY \\
\hline Insulin-like growth factor binding protein 3 & $\operatorname{lgfbp3}$ & modulates effects of insulin growth factors & 11 & DRY \\
\hline Connective tissue growth factor & Ctgf & fibrosis and extracellular matrix formation & 10 & DRY \\
\hline
\end{tabular}




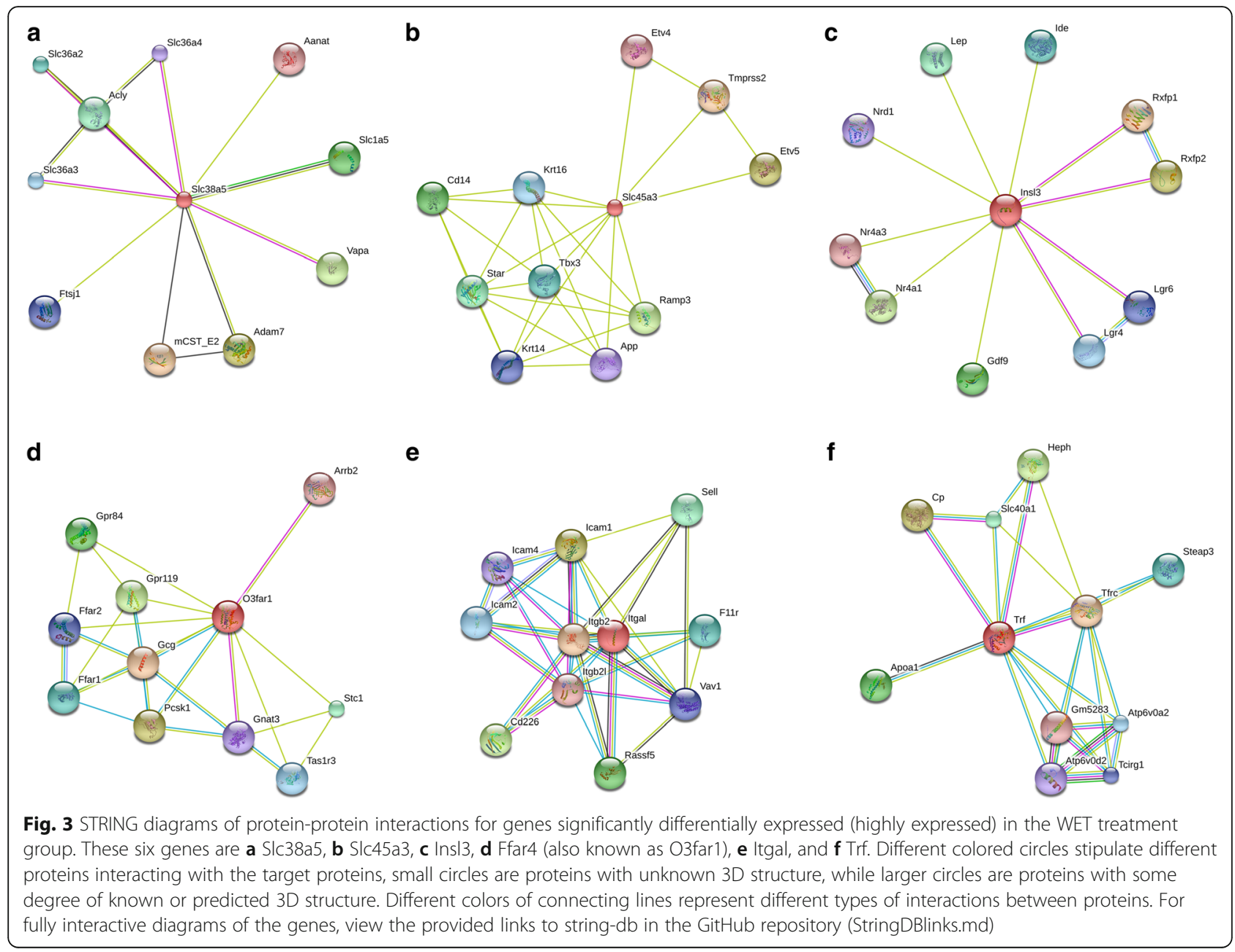

Our analysis of overall expression patterns for edgeR DGE analyzed genes by treatment indicated a strong positive correlation between normalized cpm values for genes between the WET and DRY treatments (Additional file 7: Figure S4; Adj- $\left.\mathrm{R}^{2}=0.616 ; \mathrm{F}(1,14,216)=151.132 ; p=0.00\right)$. This is indicative that the majority of genes have similar expression levels by treatment, with only a subset showing significantly differential expression (as corroborated by our previous significance testing analyses with edge $R$ and DESeq2). There were 10,307 genes in our relatively high DRY expression list, and 3806 genes in the relatively high WET expression list. However, despite this difference in genes by treatment, the PANTHER GO-Slim Molecular Function patterns of both gene sets were highly similar; namely, the percentage distributions of Molecular Function GOs was consistent between the WET and DRY gene lists (Additional file 8: Table S3). The PANTHER Overrepresentation TEST indicated significantly over- and underrepresentation of multiple PANTHER GO-Slim Biological Process categories (Additional file 9: Table S4). Of note, the category for vesicle-mediated transport (GO:0016192) was significantly over-represented in the relatively high
DRY expression gene list relative to the high WET list. This GO category includes many Ras-related proteins, which coincides with our finding of significantly elevated Rin2 expression in DRY mice. Similarly, the category for anion transport (GO:0006820) was significantly underrepresented in the relatively high DRY expression gene list relative to the high WET list. This GO category includes many SLCs, which is consistent with our finding of significantly higher SLC expression in WET mice (lower expression in DRY mice).

The a priori edgeR DGE analysis for the genes encoding nine reproductive hormones and hormone receptors did not reveal any statistically significant differences between the WET and DRY mice. The log fold change values and corresponding $p$-values for these genes are in the analysis posted on GitHub. The patterns for these genes by treatment are shown in Fig. 5.

\section{Discussion}

This is the first study to evaluate gene expression levels of a reproductive tissue (testes) in response to acute dehydration in a desert-specialized rodent, Peromyscus 


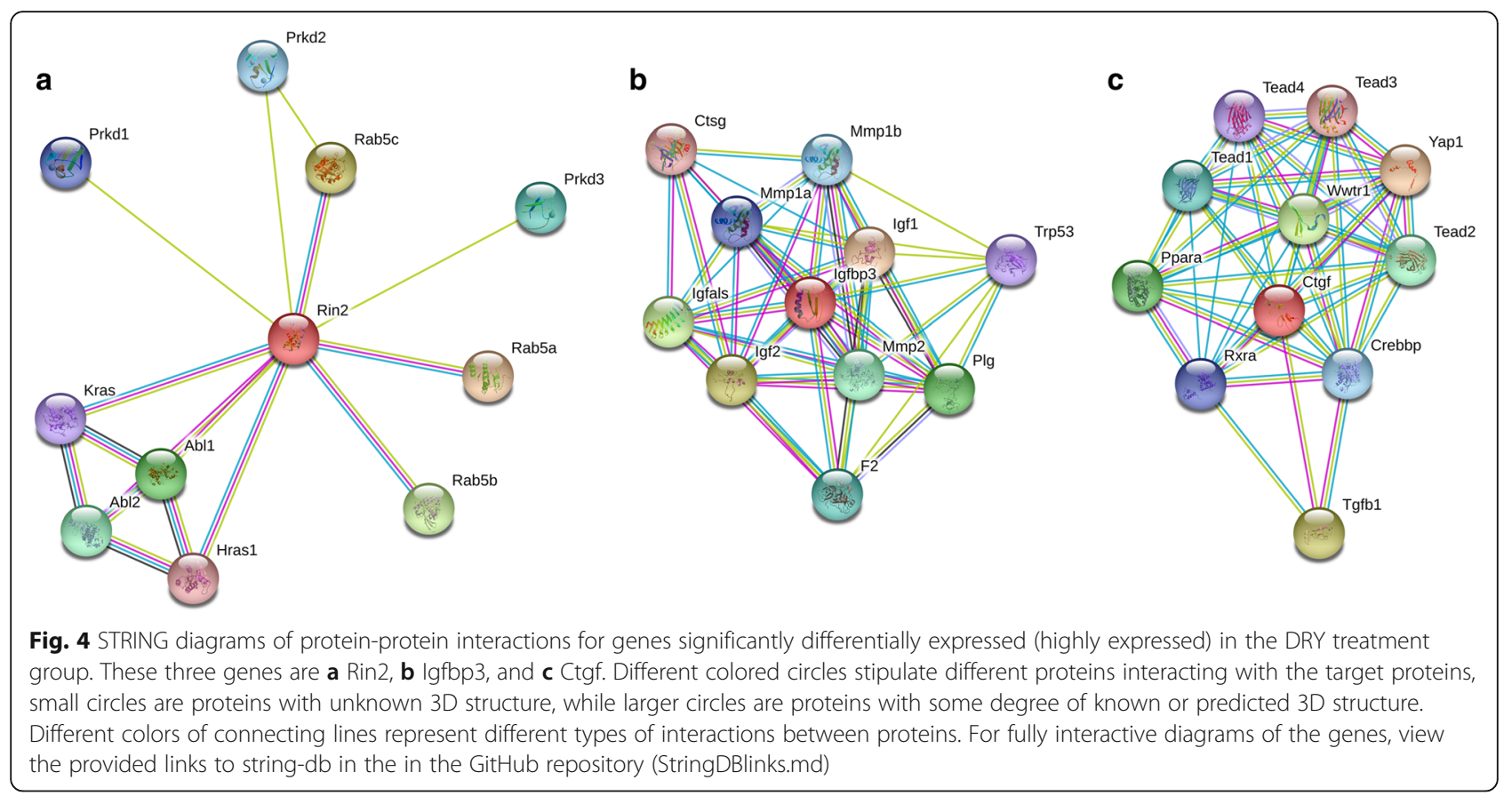

eremicus (cactus mouse). Our results demonstrate differential expression of Insl3, which is a gene linked to reproduction, but not for a small subset of other reproductive hormone (and hormone receptor) genes. We also found expression differences in two solute carrier proteins, which is consistent with previous findings asserting the importance of this protein family for osmoregulation in desert rodents. Our findings lead us to hypothesize that reproductive function may be modified via Insl3 in acutely dehydrated cactus mice. Any transcriptomic indication of potential reproductive modification in response to acute dehydration is surprising, given that this is not consistent with our understanding of $P$. eremicus as a desert specialist capable of breeding year-round in the wild. However, future studies must determine the physiological effects of decreased Insl3 expression on acutely dehydrated cactus mice. While acute dehydration is less common than chronic dehydration for desert mammals, given their ecology, it is a selective force they must overcome. Indeed, throughout much of the described range of the cactus mouse, rainfall events may occur several times per year. Cactus mice, and many other rodents, are known to rehydrate during these rainfall events (MacManes, personal observation). Following rehydration, cactus mice experience acute dehydration, followed by a steady state of chronic dehydration. The reproductive responses of cactus mice to these acute and chronic dehydration events are unknown; therefore, this study describes the transcriptomic effects of acute dehydration in testes.
Insl3, which is believed to be a hormonal regulator of fertility among mammals of both sexes, inhibits germ line apoptosis in the testes ([88-90]. Within adult rodent testes, luteinizing hormone ( $\mathrm{LH})$ stimulates expression of Insl3 in Leydig cells, and Insl3 binds to Lrg8 in seminiferous tubules, which results in inhibited apoptosis of germ-line cells, thus increasing their availability [90]. In addition, a study using murine Leydig cells demonstrated that Insl3 administration increased testosterone production [109]. The precise mechanistic role of Insl3 in modulating fertility is still being elucidated; however, researchers assert that this hormone is an important regulator of fertility in males and females (reviewed in [88]). Indeed, recent research has investigated the utility of Insl3 as an indicator of mammalian fertility (e.g. in humans: [110]; in bulls: [111]). Insl3 is also critical for the first phase of testicular descent, the transabdominal phase, which occurs during fetal development in rodents; but Insl3 does not appear to be involved in the inguinoscrotal phase which happens in sexually immature or inactive male rodents (reviewed in [112]). Lower Insl3 expression in the testes of acutely dehydrated mice leads us to suggest that fertility may be attenuated due to acute water deprivation. However, future work characterizing the functional consequences of Insl3 downregulation, including direct measurements of sperm numbers and function, is needed to causatively demonstrate reproductive attenuation. Specifically, does the number or quality of sperm decrease, and does this decrease reduce the probability of successful fertilization? 
Star

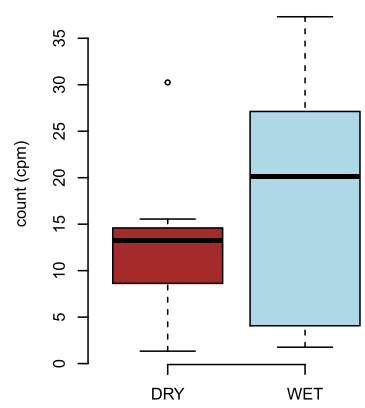

Inha

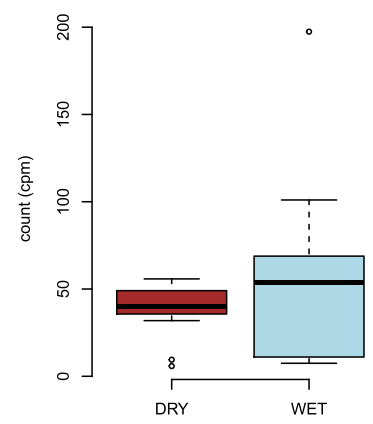

Esrra

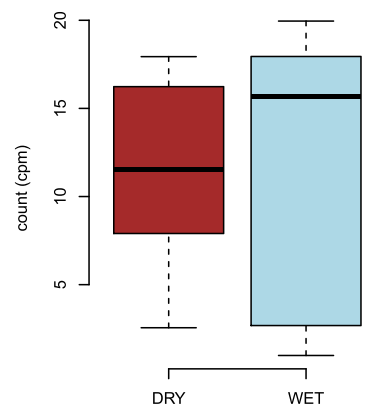

PrIr

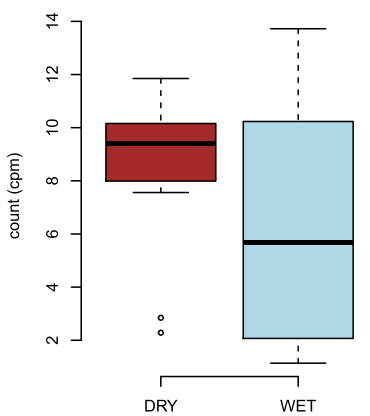

Ghrl

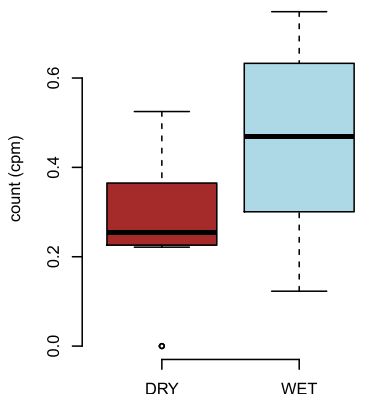

$\mathrm{Ar}$

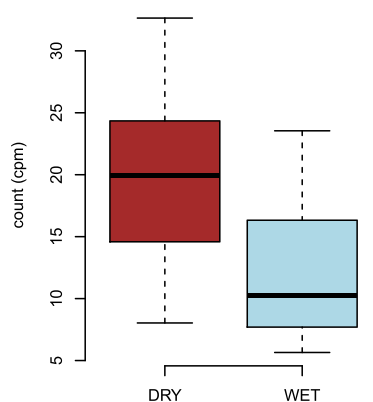

Lhger

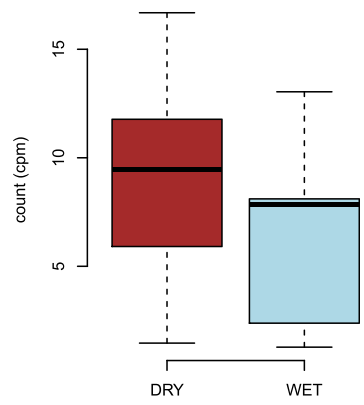

Esrrg

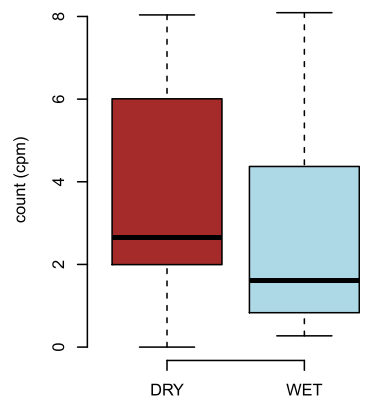

Acvr2a

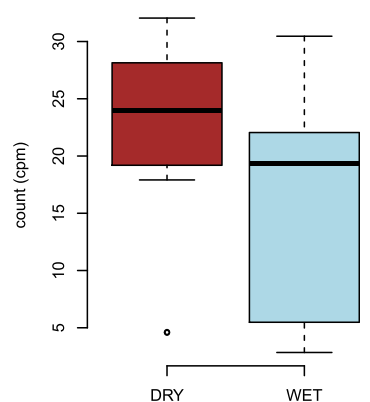

Fig. 5 Box plots of edgeR analyzed differences in gene expression by treatment for the nine a priori tested reproductive hormone and hormone receptor genes. Counts per million (cpms) for both treatments (WET and DRY) are indicated

Moreover, what are the temporal dynamics of reproductive suppression? Logically, species with core reproductive functions that are suppressed by dehydration seem likely to be rapidly outcompeted by others lacking such limitations. Given this assertion, research characterizing the reproductive correlates of chronic dehydration is a logical extension of this work, although doing so is beyond the scope of this study.

Solute carrier proteins, specifically Slc45a3 and Slc38a5, are downregulated in acute dehydration. These genes are part of a large family essential for transferring solutes across membranes (reviewed in [81-83]). Another member of this family, Solute carrier family 2 member 9 (Slc2A9), has been found to be undergoing positive selection in studies on kidney transcriptomes of cactus mouse [41] and of other desert rodents [32]. Our previous work with the male reproductive transcriptome of cactus mouse found evidence for positive selection in two additional solute carrier proteins: Slc15a3 and Slc47a1 [33]. A recent differential gene expression study in cactus mouse kidneys found that Slc2A1 and Slc8A1 also showed responses to acute dehydration [35]. Therefore, our current findings that two solute carrier proteins are lower expressed in the DRY treatment group is consistent with previous research in the kidney and male reproductive transcriptomes for this species. This leads us 
to further support the hypothesis originally proposed by Marra et al. [32] that this protein family is intrinsic to osmoregulation in desert rodents. Indeed, the findings of MacManes and Eisen [41], Kordonowy and MacManes [33], and MacManes [35] also lend support to the essential role of solute carrier proteins for maintaining homeostasis in the desert specialized cactus mouse.

In addition to their well characterized role in the maintenance of water and electrolyte balance, the differential expression of solute carrier proteins may have important reproductive consequences, particularly as they relate to hormone secretion. Indeed, the interaction between Slc38a 5 and Adam7 is relevant, because Adam7 is involved in sperm maturation and the acrosome reaction [84]. Furthermore, the protein-protein interactions between Slc45a3 with StAR and between Insl3 and Lep are of particular interest because both StAR and Lep are integral to reproduction, as well as to homeostasis (reviewed in $[87,91,113,114]$ ). However, our a priori DGE analysis evaluating StAR and other reproductive hormones did not show evidence of expression changes. Thus, the protein interactions with reproductive implications are not restricted to solute carrier proteins. The protein relationships between Itgal and intercellular adhesion molecules are also noteworthy with respect to research hypothesizing an integral role for ICAMs in spermatogenesis [97]. Furthermore, Trf is linked to Apoa1, which is a critical component of sperm activating protein $[99,100]$. While the relationship between these differentially expressed genes and the hormones involved in reproductive function are currently poorly-characterized, our findings that genes integral to sperm development and activation interact with genes differentially expressed in acute dehydration may indicate that, contrary to our expectations, acute dehydration is linked to reproductive modulation in the cactus mouse. However, functional studies will be necessary to elucidate the connection between these genes and physiological responses to dehydration. This is particularly important because many hormones have pleotropic effects, and further mechanisms of action unrelated to reproduction may be elucidated for these proteins in Peromyscus eremicus.

In contrast to genes that are down-regulated in dehydration, the genes that were upregulated in the DRY group are known to be responsible for water homeostasis and cellular growth. The significance of Rin2 is notable, because this protein is an effector for Rab5, which as a GTPase involved in vasopressin-regulated water reabsorption, a critical homeostatic process mediated through the Aqp2 water channel in kidneys [103, 104]. It is not surprising that genes in addition to solute carrier proteins, which are implicated in alternative processes for water homeostasis, are differentially expressed in response to water limitation. The other two genes that are up-regulated in the DRY treatment are indicative of modulated growth due to water limitation. Specifically, Igfb3 interacts directly with insulin growth factors responsible for tissue growth $[105,106]$, and Ctgf is linked with numerous transcription factors in the Hippo signaling pathway, which modulates apoptosis, proliferation and organ size control [108].

To complement our male centric research, future studies should evaluate dehydration induced gene expression differences in female reproductive tissues, particularly in the uterus and ovaries during various reproductive stages. Indeed, given that the physiological demands of reproduction are purportedly greater in females, though this is controversial, (Bateman's Principle: proposed in [115]; addressed in [116]; reviewed in [117]; tested in [118-120]), we would expect to see a greater degree of reproductive suppression in females. While such work is beyond the scope of this manuscript, we hope that future research will evaluate female cactus mouse reproductive responses to dehydration.

Our findings are pertinent to physiological research in other desert-rodents showing reproduction suppression in response to water limitation (reviewed in [45]), specifically, in male and female Mongolian gerbils [47] and female hoping mice [48]. The integral role of water as a reproductive cue for desert-rodents has also been demonstrated in water-supplementation studies (reviewed in $[45,50])$ as well as research on the effects of desert rainfall [51-54]. Thus, Schwimmer and Haim [46] asserted that reproductive timing is the most evolutionarily important adaptation for desert rodents. Furthermore, desert rodent research supporting a dehydration driven reproductive suppressive pathway mediated by arginine vasopressin (reviewed in [46]; tested in [121-126]) is somewhat analogous to our study linking decreased Insl3 expression in testes with dehydration, in that both findings represent non-traditional hormonal modulation of reproduction. We propose that future studies thoroughly explore physiological consequences for nontraditional hormonal pathways in response to dehydration in desert rodents, as well as well-established reproductive modulatory hormones in the hypothalamic-pituitarygonadal axis.

Emerging from this work is a hypothesis related to the reproductive response to water stress in the cactus mouse, and perhaps other desert rodents. Specifically, we hypothesize that acute dehydration may be related to reproductive mitigation; however, we hypothesize that chronic dehydration is not. Indeed, it is virtually oxymoronic to suggest that chronic dehydration, which is the baseline condition in desert animals, has negative consequences for reproductive success. Indeed, desert rodents dynamically respond to water-availability to 
initiate and cease reproductive function. Generating an integrative, systems-level understanding of the reproductive responses to both acute and chronic dehydration across desert-adapted rodents is required for testing our hypothesis. While understanding the renal response to dehydration is critical for making predictions about survival, understanding the reproductive correlates is perhaps even more relevant to evolutionary fitness. This study, to the best of our knowledge, is the first to describe the reproductive correlates of water-limitation in the cactus mouse, and the first to use a differential gene expression approach to evaluate reproductive tissue responses to drought. Furthermore, this study contributes to a research aim to determine whether novel physiological reproductive adaptations are present in male cactus mouse [33]. Developing a comprehensive understanding of reproductive responses to drought, and also the mechanisms underlying potential physiological adaptations, is necessary if we are to understand how increasing environmental variability due to climate change may modify the distribution of extant organisms $[4,17,98,105,127]$.

\section{Conclusions}

The genetic mechanisms responsible for physiological adaptations for survival and reproduction in deserts remain enigmatic. Desert rodent research has focused primarily on physiological adaptations related to survival, specifically on renal adaptations to combat extreme water-limitation. In contrast, while previous studies have investigated reproductive effects of water-limitation in desert rodents, the underlying mechanisms for physiological adaptations for reproduction during acute and chronic dehydration are unknown. Furthermore, ours is the first study to evaluate reproductive transcriptomic responses to water limitation in a desert-rodent, the cactus mouse. To this end, we characterized the reproductive correlates of acute dehydration in this desertspecialized rodent using a highly replicated RNAseq experiment. In contrast to expectations, we describe a potential signal of reproductive modulation in dehydrated male cactus mouse testes. Specifically, dehydrated mice demonstrated significantly lower expression of Insl3, which is a canonical regulator of fertility (and testes descent). Lower expression was also found in Slc45a3 and Slc38a5, lending further credence to the important role of solute carrier proteins for osmoregulation in the cactus mouse. While the low number of differentially expressed genes between acutely dehydrated and control mice might otherwise have suggested that this species is relatively unaffected by acute water-limitation, the diminished expression of Insl3 in dehydrated mice leads us to propose that acute dehydration may compromise reproductive function via decreased fertility. Indeed, we hypothesize that non-traditional reproductive hormone pathways, such as those involving Insl3 or AVP (which has elicited suppressive reproductive responses in other desert rodent research), warrant further investigation in studies evaluating the reproductive effects of acute and chronic dehydration. Although future research must experimentally evaluate the potential functional relationship between Insl3 expression patterns and reproductive function and fertility, our findings that acute-dehydration alters Insl3 expression may be concerning, particularly with respect to global climate change. Climate change driven increased variability in weather patterns may result in a greater frequency of acute water-stress, which could result in reduced reproductive function for the cactus mouse. In addition, because global climate change is predicted to shift habitats toward extremes in temperature, salinity, and aridity, and to alter species ranges, an enhanced understanding of the reproductive consequences of these changes, and of the potential for organisms to rapidly adapt, may enable us to effectively conserve innumerable species facing dramatic habitat changes.

\section{Additional files} Additional file 1: Supplemental Data. List of supplemental data files
available in DropBox and GitHub. (DOCX $40 \mathrm{~kb}$ )

Additional file 2: Table S1. Testes read data statistics, including sample identification (Mouse ID), number of reads (\# Reads), percent reads mapped to transcriptome (\% Mapping), and treatment group (TRT). Mouse ID $335 \mathrm{~T}^{*}$ is the dataset which was used to assemble the testes transcriptome; therefore, these reads were not used for the differential expression analysis. (DOCX $41 \mathrm{~kb}$ )

Additional file 3: Figure S1. Plot of edgeR determined differentially expressed genes. The 15 significant genes are in red, with positive values indicating increased expression in the DRY group, and negative values depicting increased expression in the WET group. (PDF $760 \mathrm{~kb}$ )

Additional file 4: Figure S2. Plot of edgeR determined differentially expressed transcripts. The 66 significant transcripts are in red, with positive values indicating increased expression in the DRY group, and negative values depicting increased expression in the WET group. (PDF $3703 \mathrm{~kb}$ )

Additional file 5: Figure S3. Plot of DESeq2 determined differentially expressed transcripts. The 215 significant transcripts are in red, with positive values indicating increased expression in the DRY group, and negative values depicting increased expression in the WET group. (PDF 829 kb)

Additional file 6: Table S2. Significantly differentially expressed genes identified in the three analyses (DGE in edgeR, DTE in edgeR, and DGE in DESeq2) by treatment group in P. eremicus testes. Of the 34 different genes which were more highly expressed in WET mice, six were significant across all three analyses (Gene IDs are italicized). Of the 17 genes which were more highly expressed in DRY mice, three were significant across all three analyses (Gene IDs are italicized). (DOCX $44 \mathrm{~kb}$ )

Additional file 7: Figure S4. Correlation of edgeR DGE analyzed expression patterns for all individual genes between WET and DRY treatments, as indicated by the correlation between the median values for WET and the median values for DRY normalized cpms (Adj- $R^{2}=0.616$; $F(1,14,216)=151.132 ; p=0.00)$. (PDF $710 \mathrm{~kb}$ )

Additional file 8: Table S3. PANTHER GO-Slim Molecular Function results for the relatively high DRY expression gene list and the relatively 
high WET expression gene list. Number of genes (\# WET; \# DRY), percent of gene hits against total number of function hits (\% WET; \% DRY). (DOCX $40 \mathrm{~kb}$ ) Additional file 9: Table S4. PANTHER Overrepresentation TEST GO-Slim Biological Process results for the relatively high DRY expression gene list analyzed against the high WET expression gene list as the reference list. This test reports significantly over- and under-representation of the high DRY expression gene list for multiple GO categories. For each GO term, we report the number of GO matches in both gene lists (\# WET; \# DRY) compared to the expected number of DRY matches (DRY EXP), the over- $(+)$ or under- $(-)$ representation, fold enrichment (Fold Enr), and significance ( $P$-value). (DOCX $44 \mathrm{~kb}$ )

\section{Abbreviations}

DGE: Differential gene expression; DRY: Dehydrated treatment group; DTE: Differential transcript expression; WET: Control treatment group

\section{Acknowledgments}

We would like to acknowledge the MacManes laboratory, including graduate student Andrew Lang, and the undergraduate students in the laboratory. We also acknowledge Dr. Paul Tsang for advice on the reproductive endocrinology described in the discussion and Dr. Jonathan Cummings for $\mathrm{R}$ code used in the generation of multiple figures.

\section{Funding}

This work was supported by a National Science Foundation award to Dr. Matthew MacManes (NSF IOS 1455960). Other than in providing financial support, the funding body had no role in the design, execution, interpretation or writing of the experiments described here.

\section{Availability of data and materials}

The raw reads are available at the European Nucleotide Archive under study accession number PRJEB18655. All data files, including the testes unannotated transcriptome, the dammit annotated transcriptome, and the data generated by the differential gene expression analysis (described below) are available on Dryad (doi:10.5061/dryad.743p5). All code for these analyses is also posted on Dryad (doi:10.5061/dryad.743p5).

\section{Authors' contributions}

LK and MDM both contributed to the data collection, data generation, bioinformatics, analyses, interpretation, and writing of this manuscript. Both authors read and approved the final manuscript.

\section{Competing interests}

The authors declare that they have no competing interests.

\section{Consent for publication}

\section{Not applicable.}

\section{Ethics approval}

All animal care procedures were conducted in accordance with University of New Hampshire Animal Care and Use Committee guidelines (protocol number 130902) and guidelines established by the American Society of Mammalogists [54].

\section{Publisher's Note}

Springer Nature remains neutral with regard to jurisdictional claims in published maps and institutional affiliations.

\section{Received: 19 January 2017 Accepted: 2 June 2017}

Published online: 23 June 2017

\section{References}

1. Hohenlohe PA, Bassham S, Etter PD, Stiffler N, Johnson EA, Cresko WA Population genomics of parallel adaptation in threespine stickleback using sequenced RAD Tags. PLoS Genet. 2010;6(2):e1000862. doi:10.1371/journal. pgen.1000862

2. Jones FC, Grabherr MG, Chan YF, Russell P, Mauceli E, Johnson J, et al., Broad Institute Genome Sequencing Platform, Whole Assembly Team. The genomic basis of adaptive evolution in threespine sticklebacks. Nature. 2012:484:55-61. doi:10.1038/nature10944.

3. Storz JF, Runck AM, Moriyama H, Weber RE, Fago A. Genetic differences in hemoglobin function between highland and lowland deer mice. J Exp Biol. 2010;213(15):2565-74. doi:10.1242/jeb.042598.

4. Lorenzo FR, Huff C, Myllymäki M, Olenchock B, Swierczek S, Tashi T, et al. A genetic mechanism for Tibetan high-altitude adaptation. Nat Genet. 2014;46(9):951-6. doi:10.1038/ng.3067.

5. Bedford NL, Hoekstra HE. The Natural History of Model Organisms: Peromyscus mice as a model for studying natural variation. elife. 2015;4: e06813. doi:10.7554/eLife.06813.

6. Hoekstra HE, Hirschmann RJ, Bundey RA, Insel PA, Crossland JP. A single amino acid mutation contributes to adaptive beach mouse color patterns. Science. 2006;313:101-4. doi:10.1126/science.1126121.

7. Munshi-South J, Richardson JL. Peromyscus transcriptomics: understanding adaptation and gene expression plasticity within and between species of deer mice. Semin Cell Dev Biol. 2016. in press. doi: 10.1016/j.semcdb.2016.08.011.

8. Bolger DT, Patten MA, Bostock DC. Avian reproductive failure in response to an extreme climatic event. Oecologia. 2005;142(3):398-406. doi:10.1007/ s0042-004-1734-9.

9. Evans MEK, Hearn DJ, Theiss KE, Cranston K, Holsinger KE, Donoghue MJ. Extreme environments select for reproductive assurance: evidence from evening primroses (Oenothera). New Phytol. 2010;191:555-63. doi:10.1111/j. 1469-8137.2011.03697.x

10. Martin K, Wiebe KL. Coping mechanisms of alpine and arctic breeding birds: extreme weather and limitations to reproductive resilience. Integr Comp Biol. 2004:44(2):177-85. doi:10.1093/icb/44.2.177

11. Wingfield JC, Kelley JP, Angelier F. What are extreme environmental conditions and how do organisms cope with them? Curr Zoologist. 2011;57(3):373-4. doi:10.1093/czoolo/57.3.363.

12. Asres A, Amha N. Physiological adaptation of animals to the change of environment: a review. J Biol Agric Healthc. 2014;4(25):146-51. http://www. iiste.org/Journals/index.php/JBAH/article/view/17387/17809.

13. Somero GN. The physiology of climate change: how potentials for acclimatization and genetic adaptation will determine 'winners' and losers. J Exp Biol. 2010;213:912-20. doi:10.1242/jeb037473.

14. Wingfield JC. The ecology of stress: ecological processes and the ecology of stress: the impacts of abiotic environmental factors. Funct Ecol. 2013;27:37-44. doi:10.1111/1365-2435.12039.

15. Kalabukhov NI. Comparative ecology of hibernating animals. Bull Mus Comp Zool. 1960;124:45-74.

16. Geiser F. In: Navas A, Carvalho C, Eduardo J, editors. Aestivation: molecular and physiological aspects (volume 49 in the series progress in molecular and subcellular biology). Berlin, Springer; 2010. p. 95-111. doi:10.1007/978-3642-02421-4_5

17. Stevens RD, Tello JS. Micro- and macrohabitat associations in Mojave desert rodent communities. J Mammal. 2009;90(2):388-403. doi:10.1644/08-MAMMA-141.1.

18. Fuller A, Hetem RS, Maloney SK, Mitchell D. Adaptation to heat and water shortage in large, arid-zone mammals. Physiology. 2014;29(3):159-67. doi:10.1152/physiol.00049.2013.

19. Kelt DA. Comparative ecology of desert small mammals: a selective review of the past 30 years. J Mammal. 2011;92(6):1158-78. http://dx.doi.org/10. 1644/10-MAMM-S-238.1

20. Vorhies CT. Water Requirements of Desert Animals in the Southwest. (College of Agriculture, University of Arizona, Tucson, Agricultural Experiment Station.) Technical Bulletin No. 107 1945:487-525. http://hdl. handle.net/10150/190625

21. Hill RW, Veghte JH. Jackrabbit ears: surface temperatures and vascular responses. Science. 1976;194(4263):436-8. doi:10.1126/ science. 982027

22. Schmidt-Nielsen K. In: Schmidt-Nielsen K, editor. Desert animals: physiological problems of heat and water. New York: Oxford University Press; 1964. p.129-138.

23. MacMillen RE, Hinds DS. Water regulatory efficiency in heteromyid rodents: a model and its application. Ecology. 1983;64(1):152-64. doi:10.2307/1937337.

24. Walsberg GE. Small mammals in hot deserts: some generalizations revisited. Bioscience. 2000;50(2):109-20.

25. Dantzler WH. Renal adaptations of desert vertebrates. Bioscience. 1982;32(2):108-13. doi:10.2307/1308563. 
26. Diaz GB, Ojeda RA, Rezende EL. Renal morphology, phylogenetic history and desert adaptation of South American hystricognath rodents. Funct Ecol. 2006;20:609-20. doi:10.1111/j.1365-2435.2006.01144.x.

27. Schmidt-Nielsen B, Schmidt-Nielsen K, Brokaw A, Schneiderman H. Water conservation in desert rodents. J Cell Physiol. 1948;32(3):331-60. doi:10. 1002/jcp.1030320306.

28. Marra NJ, Eo SH, Hale MC, Waser PM, DeWoody JA. A priori and a posteriori approaches for finding genes of evolutionary interest in non-model species: osmoregulatory genes in the kidney transcriptome of the desert rodent Dipodomys spectabilis (banner-tailed kangaroo rat). Comp Biochem Physiol Part D Genomics Proteomics. 2012;7(4):328-39. doi:10.1016/j.cbd.2012.07.001.

29. Schmidt-Nielsen K, Schmidt-Nielsen B. Water metabolism of desert mammals 1. Physiol Rev. 1952;32(2):135-66. PMID: http://physrev.physiology. org/content/32/2/135.

30. Urity VB, Issaian T, Braun EJ, Dantzler WH, Pannabecker TL. Architecture of kangaroo rat inner medulla: segmentation of descending thin limb of Henle's loop. Am J Phys Regul Integr Comp Phys. 2012;302(6):R720-6. doi: 10.1152/ajpregu.00549.2011.

31. Vimtrup BJ, Schmidt-Nielsen B. The histology of the kidney of kangaroo rats. Anat Rec. 1952;114(4):515-28. doi:10.1002/ar.1091140402.

32. Marra NJ, Romero A, DeWoody A. Natural selection and the genetic basis of osmoregulation in heteromyid rodents as revealed by RNA-seq. Mol Ecol. 2014;23(11):2699-711. doi:10.1111/mec.12764.

33. Kordonowy LK, MacManes MD. Characterization of a male reproductive transcriptome for Peromyscus eremicus (cactus mouse). PeerJ. 2016;4:e2617. doi:10.7717/peerj.2617

34. Kordonowy L, Lombardo K, Green H, Dawson, MD, Bolton E, LaCourse S, MacManes M. Physiological and biochemical changes associated with acute experimental dehydration in the desert adapted mouse, Peromyscus eremicus. Physiol Rep. 2017; 5(e13218). http//physreports.physiology.org/content/5/6/e13218.long.

35. MacManes MD. Severe acute dehydration in a desert rodent elicits a transcriptional response that effectively prevents kidney injury. Am J Physiol Ren Physiol. 2017;(April 5) doi:10.1152/ajprenal.00067.2017. in press

36. King, JA, (editor). Biology of Peromyscus (Rodentia). Special Publication No. 2, The American Society of Mammologists, 1968. doi: 10.2307/1378817.

37. MacMillen RE, Garland T Jr. In: Kirkland Jr LG, Layne JN, editors. Advances in the study of Peromyscus (Rodentia). Lubbock: Texas Tech University Press; 1989. p. 143-68.

38. Caire W. Cactus mouse. In: Wilson D, Ruff S, editors. The smithsonian book of North American mammals. Washington, D.C.: Smithsonian Institution Press; 1999. p. 567-8.

39. Veal R, Caire W. Peromyscus eremicus. Mamm Species. 1979;118:1-6. http:// www.science.smith.edu/msi/pdf/i0076-3519-118-01-0001.pdf

40. Dewey GC, Elias H, Appel KR. Stereology of renal corpuscles of desert and swamp deermice. Nephron. 1966;3(6):352-65. doi:10.1159/000179552.

41. MacManes MD, Eisen MB. Characterization of the transcriptome, nucleotide sequence polymorphism, and natural selection in the desert adapted mouse Peromyscus eremicus. PeerJ 2014;2:e642. org/10.7717/peerj.642.

42. Ahmed A, Tiwari RJ, Mishra GK, Jena B, Dar MA, Bhat AA. Effect of environmental heat stress on reproductive performance of dairy cows- a review. Int J Livest Res. 2015;5(4):10-8. doi:10.5455/ij|r.20150421122704.

43. Nargund $\mathrm{VH}$. Effects of psychological stress on male fertility. Nat Rev Urol. 2015;12:373-82. doi:10.1038/nrurol.2015.112.

44. Wingfield JC, Sapolsky RM. Reproduction and resistance to stress: when and how. J Neuroendocrinol. 2003;15:711-24. doi:10.1046/j.1365-2826.2003.01033.x.

45. Bales KL, Hostetler CM. Hormones and Reproductive Cycles in Rodents. In: Norris DO, Lopez KH, editors. Hormones and reproduction of vertebrates: volume 5 mammals. London: Academic Press (Elsevier); 2011. p. 215-40.

46. Schwimmer $\mathrm{H}$, Haim A. Physiological adaptations of small mammals to desert ecosystems. Integr Zool. 2009;4:357-66. doi:10.1111/j.1749-4877.2009.00176.x.

47. Yahr P, Kessler S. Suppression of reproduction in water-deprived Mongolian gerbils (Meriones unguiculatus). Biol Reprod. 1975;12(2):249-54. https://doi. org/10.1095/biolreprod12.2.249

48. Breed WG. Environmental factors and reproduction in the female hopping mouse, Notomys alexis. J Soc Reprod Fertil. 1975;45:273-81. doi:10.1530/jff.0.0450273.

49. El-Bakry HA, Zahran WM, Bartness TJ. Control of reproductive and energetic status by environmental cues in a desert rodent, Shaw's jird. Physiol Behav. 1999;66(4):657-66. http://doi.org/10.1016/S0031-9384(98)00344-8

50. Christian DP. Comparative demography of three Namib desert rodents: Responses to the provision of supplementary water. J Mammal. 1979;60(4): 679-90. https://doi.org/10.2307/1380185
51. Sarli J, Lutermann H, Alagali AN, Mohammed OB, Bennett NC. Seasonal reproduction in the Arabian spiny mouse, Acomys dimidiatus (Rodentia: Muridae) from Saudi Arabia: the role of rainfall and temperature. J Arid Environ. 2016;124:352-9. http://dx.doi.org/10.1016/j.jaridenv.2015.09.008

52. Sarli J, Lutermann H, Alagali AN, Mohammed OB, Bennett NC. Reproductive patterns in the Baluchistan gerbil, Gerbillus nanus (Rodentia: Muridae), from western Saudi Arabia: the role of rainfall and temperature. J Arid Environ. 2015;113:87-94. http://dx.doi.org/10.1016/j.jaridenv.2014.09.007

53. Henry O, Dubost G. Breeding periods of Gerbillus cheesmani (Rodentia, Muridae) in Saudi Arabia. Mammalia. 2012;76(4):383-7. doi:10.1515/ mammalia-2012-0017.

54. Breed WG, Leigh CM. Reproductive biology of an old endemic murid rodent of Australia, the Spinifex hopping mouse, Notomys alexis: adaptations for life in the arid zone. Integr Zool. 2011;6:321-33. doi:10.1111/ j.1749-4877.2011.00264x.

55. Sikes RS, Animal Care and Use Committee of the American Society of Mammalogists. Guidelines of the American society of Mammalogists for the use of wild mammals in research and education. J Mammal. 2016;97(3):66388. doi:10.1093/jmammal/gyw078.

56. MacManes MD. Establishing evidenced-based best practice for the de novo assembly and evaluation of transcriptomes from non-model organisms. bioRxiv 2016. doi: 10.1101/035642.

57. Song L, Florea L. Rcorrector: efficient and accurate error correction for Illumina RNA-seq reads. Gigascience. 2015;4:48. doi:10.1186/s13742-015-0089-y.

58. MacManes MD. On the optimal trimming of high-througput mRNA sequence data. Front Genet 2014;5:13. doi: org/10.3389/fgene.2014.00013.

59. Jiang H, Lei R, Ding S-W, Zhu S. Skewer: a fast and accurate adapter trimmer for next-generation sequencing paired-end reads. BMC Bioinf. 2014;15:182. doi:10.1186/1471-2015-15-182.

60. Liu J, Li G, Chang Z, Yu T, Liu B, McMullen R, et al. BinPacker: packing-based de novo transcriptome assembly from RNA-seq data. PLoS Comput Biol. 2016;12(2):e1004772. doi:10.1371/journal.pcbi.1004772.

61. Fu L, Niu B, Zhu Z, Wu S, Li W. CD-HIT: accelerated for clustering the next generation sequencing data. Bioinformatics. 2012;28(23):3150-2. doi:10. 1093/bioinformatics/bts565.

62. Li W, Godzik A. Cd-hit: a fast program for clustering and comparing large sets of protein or nucleotide sequences. Bioinformatics. 2006;22(13):1658-9. doi:10.1093/bioinformatics/btl158.

63. Smith-Unna R, Boursnell C, Patro R, Hibberd JM, Kelley S. TransRate: reference free quality assessment of de-novo transcriptome assemblies. Genome Res. 2016;26:1134-44. doi:10.1101/gr.196469.115.

64. Simão FA, Waterhouse RM, loannidis P, Kriventseva EV, Zdobnov EM. BUSCO: assessing genome assembly and annotation completeness with single-copy orthologs. Bioinformatics. 2015;31(19):3210-2. doi:10.1093/ bioinformatics/btv351.

65. Patro R, Duggal G, Kingsford C. Salmon: accurate, versatile and ultrafast quantification from RNA-seq data using lightweight-alignment. bioRxiv. 2015. doi: http://dx.doi.org/10.1101/021592.

66. Froussios K, Schurch NJ, Mackinnon K, Gierlinski M, Duc C, Simpson GG, Barton GJ. How well do RNA-Seq differential gene expression tools perform in higher eukaryotes? bioRxiv. 2016. doi: 10.1101/090753.

67. Gierliński M, Cole C, Schofield P, Schurch NJ, Sherstnev A, Singh V, et al. Statistical models for RNA-seq data derived from a two-condition 48replicate experiment. Bioinformatics. 2015;31(22):3625-30. doi:10.1093/ bioionformatics/btv425.

68. Schurch NJ, Schofield P, Gierliński M, Cole C, Sherstnev A, Singh V, et al. How many biological replicates are needed in an RNA-seq experiment and which differential expression tool should you use? RNA. 2016;22(6):839-51. doi:10.1261/rna.053959.115.

69. Soneson C, Love MI, Robinson MD. Differential analyses for RNA-seq: transcript-level estimates improve gene-level inferences. F1000Reserach. 2016:4:1521. doi:10.12688/f1000research.7563.2.

70. McCarthy DJ, Chen Y, Smyth GK. Differential expression analysis of multifactor RNA-Seq experiments with respect to biological variation. Nucleic Acids Res. 2012;40(10):4288-97. doi:10.1093/nar/gks042.

71. Robinson MD, McCarthy DJ, Smyth GK. edgeR: a Bioconductor package for differential expression analysis of digital gene expression data. Bioinformatics. 2010;26(1):139-40. doi:10.1093/bioninformatics.btp616.

72. Love MI, Huber W, Anders S. Moderated estimation of fold change and dispersion for RNA-seq data with DESeq2. Genome Biol. 2014;15:550. doi:10. 1186/s13059-014-0550-8. 
73. R Core Team. R: a language and environment for statistical computing. Vienna: R Foundation for Statistical Computing; 2016. https://www.R-project.org

74. Altschul SF, Gish W, Miller W, Myers EW, Lipman DJ. Basic local alignment search tool. J Mol Biol. 1990:215(3):403-10. doi:10.1016/S00222836(05)80360-2.

75. Madden T. [Updated 2003 Aug 13]. The BLAST Sequence Analysis Tool. In: McEntyre J, Ostell J, editors. The NCBI Handbook [Internet]. Bethesda: National Center for Biotechnology Information (US); 2002-. Chapter 16. Available from: http://www.ncbi.nlm.nih.gov/books/NBK21097/.

76. Benjamini $Y$, Hochberg Y. Controlling the false discovery rate: a practical and powerful approach to multiple testing. J R Stat Soc Ser B Methodol. 1995;57(1):289-30. http://www.jstor.org/stable/2346101

77. Snel B, Lehmann G, Bork P, Huynen MA. STRING: a web-server to retrieve and display the repeatedly occurring neighbourhood of a gene. Nucleic Acids Res. 2000;28(18):3442-4. doi:10.1093/nar/28.18.3442

78. Szklarczyk D, Franceschini A, Wyder S, Forslund K, Heller D, Huerta-Cepas J, et al. STRING v10: protein-protein interaction networks, integrated over the tree of life. Nucleic Acids Res. 2015;43:D447-52. doi:10.1093/nar/gku1003.

79. Mi H, Muruganujan A, Casagrande JT, Thomas PD. Large-scale gene function analysis with the PANTHER classification system. Nat Protoc. 2013;8: 1551-66. doi:10.1038/nprot.2013.092.

80. Mi H, Huang X, Muruganujan A, Tang H, Mills C, Kang D, et al. PANTHER version 11: expanded annotation data form gene ontology and reactome pathways, and data analysis tool enhancements. Nucleic Acids Res. 2017; 45(D1):D183-9. doi:10.1093/nar/gkw1138.

81. César-Razquin A, Snijder B, Frappier-Brinton T, Isserlin R, Gyimesi G, Bai X, et al. A call for systematic research on solute carriers. Cell. 2015;162(3):478-87. doi:10.1016/j.cell.2015.07.022

82. Hediger MA, Romero MF, Peng J-B, Rolfs A, Takanaga H, Bruford EA. The $A B C s$ of solute carriers: physiological, pathological and therapeutic implications of human membrane transport proteins: introduction. Pffugers Archiv. 2004;447(5):465-548. doi:10.1007/s00424-003-1192-y.

83. Hediger MA, Clemencon B, Burrier RE, Bruford EA. The ABCs of membrane transporters in health and disease (Slc series): introduction. Mol Asp Med. 2013;34(2-3):95-107. doi:10.1016/j.mam.2012.12.009.

84. Schiöth HB, Roshanbin S, Hägglund MG, Fredriksson R. Evolutionary origin of amino acid transporter families Slc32, Slc36 and SIc38 and physiological, pathological and therapeutic aspects. Mol Asp Med. 2013;34(2-3):571-85. doi:10.1016/j.mam.2012.07.012.

85. Vitavska O, Wieczorek $\mathrm{H}$. The Slc45 gene family of putative sugar transporters. Mol Asp Med. 2013;34(2-3):655-60. doi:10.1016/j.mam.2012.05.014

86. Oh J, Woo JM, Choi E, Kim T, Cho BN, Park ZY, et al. Molecular, biochemical, and cellular characterization of epididymal ADAMs, Adam7 and ADAM28. Biochem Biophys Res Commun. 2005;331(4):1374-83. doi:10.1016/j.bbrc. 2005.04.067

87. Christenson LK, Strauss JF III. Steroidogenic acute regulatory protein: an update on its regulation and mechanism of action. Arch Med Res. 2001; 32(6):576-86. http://dx.doi.org/10.1016/S0188-4409(01)00338-1

88. Bathgate RAD, Zhang S, Hughes RA, Rosengren KJ, Wade JD. The Structural Determinants of Insulin-Like Peptide 3 Activity. Front Endocrinol. 2012;3:11. doi:10.3389/fendo.2012.00011

89. Bathgate RAD, Halls ML, van der Westhuizen ET, Callander GE, Kocan M, Summers RJ. Relaxin family peptides and their receptors. Physiol Rev. 2013; 93(1):405-80. doi:10.1152/physrev.00001.2012.

90. Kawamura K, Kumagai J, Sudo S, Chun S-Y, Pisarska M, Morita H, Toppari J, Fu P, Wade JD, Bathgate RAD, Hsueh AJW. Paracrine regulation of mammalian oocyte maturation and male germ cell survival. Proc Natl Acad Sci 2004;101(19): 7323-7328. doi: 10.1073.pnas.0307061101.

91. Friedman J. 20 Years of leptin: lepttin at 20: an overview. J Endocrinol. 2014; 223:1T1-8. doi:10.1530/JOE-14-0405

92. Moniri NH. Free-fatty acid receptor-4 (GPR120): cellular and molecular function and its role in metabolic disorders. Biochem Pharmacol. 2016;110111:1-15. doi:10.1016/j.bcp.2016.01.021.

93. Wagner GF, Dimattia GE. The stanniocalcin family of proteins. J Exp Zool A. 2006;305A(9):769-80. doi:10.1002/jez.a.313.

94. Chang ACM, Cha J, Koentgen F, Reddel RR. The murine stanniocalcin 1 gene is not essential for growth and development. Mol Cell Biol. 2005;25(3): 10604-10. doi:10.1128/MCB.25.23.10604-10610.2005.

95. Bose TO, Colpitts SL, Pham Q-M, Puddington L, Lefrancois L. CD11a is essential for normal development of hematopoietic intermediates. Immunol. 2014;193:2863-72. doi:10.4049/jimmunol.1301820.
96. Albelda SM, Smith CW, Ward PA. Adhesion molecules and inflammatory injury. FASEB J. 1994;8(8):504-12.

97. Xiao X, Mruk DD, Cheng CY. Intercellular adhesion molecules (ICAMs) and spermatogenesis. Hum Reprod Update. 2013;19(2):167-86. doi:10.1093/ humupd/dms049.

98. Gkouvatsos K, Papanikolaou G, Pantopoulos K. Regulation of iron transport and the role of transferrin. Biochim Biophys Acta Gen Subj. 2012;1820(3): 188-202. doi:10.1016/j.bhagen.2011.10.013.

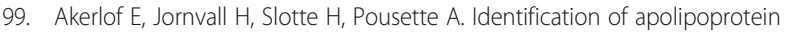
A1 and immunoglobulin as components of a serum complex that mediates activation of human sperm motility. Biochemistry. 1991;30:8986-90. doi:10.1021/bi00101a011

100. Leijonhufvud P, Akerlof E, Pousette A. Structure of sperm activating protein. Mol Hum Reprod. 1997;3(3):249-53. doi:10.1093/molehr/3.3.249.

101. Doherty GJ, McMahon HT. Mechanisms of Endocytosis. Annu Rev Biochem. 2009;78:857-902. doi:10.1146/annurev.biochem.78.081307.110540.

102. Stenmark H, Olkkonen VM. The Rab GTPase family. Genome Biol. 2001:2(5). doi:10.1186/gb-2001-2-5-reviews3007.

103. Boone M, Deen PMT. Physiology and pathophysiology of the vasopressinregulated renal water reabsorption. Pflugers Archiv. 2008;456(6):1005-24. doi:10.1007/s00424-008-0498-1.

104. Kwon T-H, Frokiaer J, Nielsen S. Regulation of aquaporin-2 in the kidney: a molecular mechanism of body-water homeostasis. Kidney Res Clin Pract. 2013;32(3):96-1023. doi:10.1016/j.krcp.2013.07.005.

105. Le Roith D. Insulin-like growth factors. N Engl J Med. 1997;336(9):633-40. doi:10.1056/NEJM199702273360907.

106. Jones Jl, Clemmons DR. Insuline-like growth factors and their biding proteins: biological actions. Endocr Rev. 2008;16(1) doi:10.1210/edrv-16-1-3.

107. Moussad EE-DA, Brigstock DR. Connective tissue growth factor: what's in a name? Mol Genet Metab. 2000;71:276-92. doi:10.1006/mgme.2000.3059.

108. Pan D. The hippo signaling pathway in development and cancer. Dev Cell. 2010;19(4):491-505. doi:10.1016/j.devcel.2010.09.011.

109. Pathirana IN, Kawte N, Bullesbach EE, Takahashi M, Hatoya S, Inaba T, et al. Insulin-like peptide 3 stimulates testosterone secretion in mouse Leydig cells via CAMP pathway. Regul Pept. 2012;178(1-3):102-6. https://doi.org/10. 1016/j.regpep.2012.07.003

110. Kovac JR, Lipshultz LI. The significance of insulin-like factor 3 as a marker of intratesticular testosterone. Fertil Steril 2013;99(1):66-67. doi: 10.1016/j. fertnstert.2012.09.009.

111. Pitia AM, Uchiyama K, H S, Kinukawa M, Minato $Y$, Sasada $H$, et al. Functional insulin-like factor 3 (InsI3) hormone-receptor system in the testes and spermatozoa of domestic ruminants and its potential as a predictor of sire fertility. Anim Sci J. 2017;88(4):678-90. doi:10.1111/asj.12694.

112. Hutson JM, Li R, Southwell BR, Newgreen D, Cousinery M. Regulation of testicular descent. Pediatr Surg Int. 2015;31(4):317-25. doi:10.1007/s00383015-3673-4

113. Allison MB, Myers MG Jr. 20 years of leptin: connecting leptin signaling to biological function. J Endocrinol. 2014;223(1):T25-35. doi:10.1530/JOE-14-0404.

114. Anuka E, Gal M, Stocco DM, Orly J. Expression and roles of steroidogenic acute regulatory (StAR) protein in 'non-classical', extra-adrenal and extragonadal cells and tissues. Mol Cell Endocrinol. 2013;371(1-2):47-61. doi:10. 1016/j.mce.2013.02.003.

115. Bateman AJ. Intra-sexual selection in Drosophila. Heredity. 1948;2:349-68.

116. Trivers RL. Parental Investment and Sexual Selection. In: Campbell B, editor. Sexual selection and the descent of man. Chicago: Aldine; 1972. p. 136-77.

117. Knight J. Sexual Stereotypes. Nature. 2002;415:254-6. doi:10.1038/415254a.

118. Collet JM, Dean RF, Worley K, Richardson DS, Pizzari T. The measure and significance of Bateman's principles. Proc R Soc B Biol Sci. 2014:281(1782). doi:10.1098/rspb.2013.2973.

119. Jones AG, Arguello JR, Arnold SJ. Validation of Bateman's principles: a genetic study of sexual selection and mating patterns in the roughskinned newt. Proc R Soc B Biol Sci. 2002;269(1509):2533-9. doi:10.1098/ rspb.2002.2177.

120. Jones AG, Rosenqvist G, Berglund A, Avise JC. The measurement of sexual selection using Bateman's principles: an experimental test in the sex-role reversed pipefish Syngnathus typhle. Integr Comp Biol. 2005:45(5):874-84. doi:10.1093/icb/45.5.874

121. Bukovetzky E, Fares F, Schwimmer H, Haim A. Reproductive and metabolic responses of desert adapted common spiny male mice (Acomys cahirinus) to vasopressin treatment. Comp Biochem Physiol. 2012a;162(4):349-56. http://doi.org/10.1016/j.cbpa.2012.04.007 
122. Bukovetzky E, Schwimmer H, Fares F, Haim A. Photoperiodicity and increasing salinity as environmental cues for reproduction in desert adapted rodents. Horm Behav. 2012b;61(1):84-90. http://doi.org/10.1016/j.yhbeh. 2011.10.006

123. Shanas U, Haim A. Diet salinity and vasopressin as reproductive modulators in the desert-dwelling golden spiny mouse (Acomys russatus). Physiol Behav. 2004;81(4):645-50. doi:10.1016/j.physbeh.2004.03.002.

124. Tahri-Joutei A, Pointis G. Modulation of mouse Leydig cell steroidogenesis through a specific arginine-vasopressin receptor. Life Sci. 1988a;43(2):177-85. doi:10.1016/0024-3205(88)90295-0.

125. Tahri-Joutei A, Pointis G. Time-related effects of arginine vasopressin on steroidogenesis in cultured mouse Leydig cells. J Soc Reprod Fertil. 1988b;82:247-54. doi:10.1530/jrf.0.0820247.

126. Wube T, Fares F, Haim A. A differential response in the reproductive system and energy balance of spiny mice Acomys populations to vasopressin treatment. Comparative biochemistry and physiology. part A. Mol Integr Physiol. 2008;151:499-504. doi:10.1016/j.cbpa.2008.06.027.

127. Scott C. dammit: an open and accessible de novo transcriptome annotator. 2016. https://github.com/camillescott/dammit

Submit your next manuscript to BioMed Central and we will help you at every step:

- We accept pre-submission inquiries

- Our selector tool helps you to find the most relevant journal

- We provide round the clock customer support

- Convenient online submission

- Thorough peer review

- Inclusion in PubMed and all major indexing services

- Maximum visibility for your research

Submit your manuscript at www.biomedcentral.com/submit
Biomed Central 